\title{
Heme on innate immunity and inflammation
}

\section{Fabianno F. Dutra* and Marcelo T. Bozza*}

Laboratório de Inflamação e Imunidade, Departamento de Imunologia, Instituto de Microbiologia, Universidade Federal do Rio de Janeiro, Rio de Janeiro, Brazil

\section{Edited by:}

Raffaella Gozzelino, Instituto

Gulbenkian de Ciência, Portugal

\section{Reviewed by:}

Leo Otterbein, Beth Israel Deaconess Medical Center/Harvard Medical School, USA

Viktória Jeney, University of

Debrecen, Hungary

\section{*Correspondence:}

Fabianno F. Dutra and Marcelo T.

Bozza, Laboratório de Inflamação e Imunidade, Departamento de

Imunologia, Instituto de Microbiologia, Universidade Federal do Rio de Janeiro, Avenida Carlos Chagas Filho, 373, Rio de Janeiro 21941-902, Brazil e-mail: fabianno44@yahoo.com.br; mbozza@micro.ufrj.br
Heme is an essential molecule expressed ubiquitously all through our tissues. Heme plays major functions in cellular physiology and metabolism as the prosthetic group of diverse proteins. Once released from cells and from hemeproteins free heme causes oxidative damage and inflammation, thus acting as a prototypic damage-associated molecular pattern. In this context, free heme is a critical component of the pathological process of sterile and infectious hemolytic conditions including malaria, hemolytic anemias, ischemiareperfusion, and hemorrhage. The plasma scavenger proteins hemopexin and albumin reduce heme toxicity and are responsible for transporting free heme to intracellular compartments where it is catabolized by heme-oxygenase enzymes. Upon hemolysis or severe cellular damage the serum capacity to scavenge heme may saturate and increase free heme to sufficient amounts to cause tissue damage in various organs. The mechanism by which heme causes reactive oxygen generation, activation of cells of the innate immune system and cell death are not fully understood. Although heme can directly promote lipid peroxidation by its iron atom, heme can also induce reactive oxygen species generation and production of inflammatory mediators through the activation of selective signaling pathways. Heme activates innate immune cells such as macrophages and neutrophils through activation of innate immune receptors. The importance of these events has been demonstrated in infectious and non-infectious diseases models. In this review, we will discuss the mechanisms behind heme-induced cytotoxicity and inflammation and the consequences of these events on different tissues and diseases.

Keywords: heme, iron, hemolysis, ROS, inflammation, innate immunity, programed cell death, cytotoxicity

\section{HEME PHYSIOLOGY}

Heme consists of a tetrapyrrole ring with an iron $(\mathrm{Fe})$ atom bound in the center, coordinated to the pyrrole rings (Kumar and Bandyopadhyay, 2005). Heme is present in organisms of all kingdoms being the prosthetic group of several proteins fundamental for the life of aerobic organisms (Wagener et al., 2003b). In vertebrates, heme is ubiquitously expressed and its functions are determined by the polypeptide interacting with it (Dawson, 1988). The capacity of the chelated Fe to undergo a reversible change in the oxidation state renders heme a versatile biological catalyst acting in oxidative reactions, electron transfer processes, and delivering molecular oxygen $\left(\mathrm{O}_{2}\right)$ to cells (Ryter and Tyrrel, 2000). Heme is presented in different forms, mostly in forms $a, b$, and $c$. Heme $a$ and $c$ are important in the physiology of electron transport and are found in cytochrome $c$ oxidase (Tsukihara et al., 1995) and cytochrome $c$ reductase (Xia et al., 1997; Zhang et al., 1998), respectively. Heme $b$ is the most common type in mammals and is part of several proteins (Larsen et al., 2012) including the gas carriers hemoglobin (Hb; Park et al., 2006) and myoglobin (Evans and Brayer, 1988; Vojtechovsky et al., 1999), hemeproteins related to heme release during hemolysis and tissue damage. Importantly, heme $b$ interaction with heme oxygenase (HO; Lad et al., 2003), the enzyme responsible for heme intracellular catabolism, and hemopexin (Hx; Paoli et al., 1999), a plasmatic heme scavenger, is essential for the regulation of free heme availability and Fe recycling (Kovtunovych et al., 2010; Tolosano et al., 2010).
Besides its physiological importance, heme has a potent oxidative capacity oxidizing lipids (Tappel, 1953, 1955; Vincent et al., 1988) and proteins (Aft and Mueller, 1984; Vincent, 1989), and damaging DNA (Aft and Mueller, 1983). Thus, heme can be a dangerous molecule once released from hemeproteins. Some diseases are characterized by high amounts of hemeproteins out from their physiological environments. The consequences of heme toxicity can be appreciated in hemolytic diseases such as $\beta$-thalassemia, sickle-cell disease (SCD), ischemia-reperfusion (IR), and malaria (Katori et al., 2002; Pamplona et al., 2007; Vinchi et al., 2013). Extracellular and intracellular proteins have essential functions controlling free heme availability, guarding tissues from its deleterious effects. Through evolution mammals acquired several protective mechanisms against heme toxicity. Under physiologic conditions or mild to moderate hemolysis, haptoglobin (Hp) binds Hb (Melamed-Frank et al., 2001). Because of its large molecular size, this complex is maintained in the intravascular space, preventing the association of otherwise free $\mathrm{Hb}$ with nitric oxide (NO; Reiter et al., 2002) and inhibiting the release of free heme (Melamed-Frank et al., 2001). The complex Hp:Hb binds to CD163 (Kristiansen et al., 2001), present in macrophages and hepatocytes (Philippidis et al., 2004; Quaye, 2008), which mediates the endocytosis of $\mathrm{Hb}-\mathrm{Hp}$ complexes for degradation. However, during hemolytic diseases high amounts of $\mathrm{Hb}$ are released in the intravascular environment, saturating the $\mathrm{Hp}$ molecules and thus accumulating free $\mathrm{Hb}$ (Muller-Eberhard, 1970). In the presence of reactive oxygen species (ROS), $\mathrm{Hb}$ is oxidized to methemoglobin 
(MetHb; Balla et al., 1993), characterized by the change in the oxidative state of the Fe present in the heme molecule from ferrous $\left(\mathrm{Fe}^{+2}\right)$ to ferric $\left(\mathrm{Fe}^{+3}\right)$. MetHb is unstable and rapidly releases free heme (Balla et al., 1993). In this context, Hx scavenges free heme, binding it with very high affinity (Paoli et al., 1999). Hx inhibits the oxidative property of heme (Eskew et al., 1999) and mediates heme transportation to intracellular compartments through the macrophage receptor CD91 (Hvidberg et al., 2005), a critical step on heme catabolism. Once inside the cells, heme is catabolized by $\mathrm{HO}$ enzymes, generating equimolar amounts of biliverdin, carbon monoxide (CO), and Fe (Tenhunen et al., 1968). Differently from biliverdin and $\mathrm{CO}$, which have anti-inflammatory effects (Otterbein et al., 2000; Baranano et al., 2002), free Fe is highly oxidative and can promote free radicals generation through the Fenton reaction, which catalyzes hydroxyl radicals from the reaction of $\mathrm{Fe}$ with $\mathrm{H}_{2} \mathrm{O}_{2}$ (Fenton, 1894). These radicals initiate lipid-chain peroxidation by obtaining electrons from other molecules, including unsaturated fatty acid (RH), generating an alkyl radical (R•; Ryter and Tyrrel, 2000). Thus, labile Fe can induce cytotoxic effects (Gozzelino et al., 2012). In this context, the $\mathrm{HO}$ function is complemented by ferritin, a ubiquitous intracellular protein complex that stores Fe in a soluble and non-toxic form (Eisenstein et al., 1991). Ferritin is composed of a heavy and a light chain which cooperates in the overall uptake and store of Fe in a non-toxic form protecting cells from hydroxyl radicals generated through the Fenton reaction (Arosio et al., 2009). While the ferritin heavy chain $(\mathrm{FtH})$ presents a ferroxidase activity that converts the $\mathrm{Fe}$ from $\mathrm{Fe}^{+2}$ into $\mathrm{Fe}^{+3}$ (Broxmeyer et al., 1991), the ferritin light chain (FtL) is essential to promote Fe nucleation (Levi et al., 1992). Cells deficient on FtH are more susceptible to oxidative damage, while increased amounts of $\mathrm{FtH}$ protects cells from death induced by challenges such as Fe, tumor necrosis factor (TNF), heme, heme plus TNF, or oxidized low-density lipoprotein (LDL; Juckett et al., 1995; Pham et al., 2004; Gozzelino et al., 2012). All these effects require the ferroxidase activity of FtH.

Not only vertebrates need to manage high amounts of free heme. Hematophagous arthropods, upon digestion of $\mathrm{Hb}$ in the mid-gut, are exposed to enormous quantities of free heme and ROS. Different blood-sucking species have developed independent adaptations to deal with heme toxicity, including heme aggregation (Oliveira et al., 1999), heme degradation (Paiva-Silva et al., 2006; Pereira et al., 2007), expression of heme-binding proteins (Oliveira et al., 1995), and induction of antioxidant systems (Paes et al., 2001; Oliveira et al., 2011).

\section{DIRECT CYTOTOXIC EFFECTS OF HEME}

The cytotoxicity of heme was initially associated with a direct effect due to its structural properties, specifically the capacity of the hydrophobic porphyrin ring to intercalate lipid layers and the presence of the atom of $\mathrm{Fe}$, considered essential for heme-induced ROS generation. Heme can destabilize biological membranes increasing its permeability and the chance of lysis (Schmitt et al., 1993), as it happens with erythrocytes (Chiu and Lubin, 1989). This effect relies in the amphipathic properties of the porphyrin ring rendering heme the tendency to allocate in non-polar niches including lipoproteins and lipid membranes where it might establish dangerous contacts with lipids, important targets of peroxidation by ROS (Rose et al., 1985; Light and Olson, 1990a,b). Once intercalated into cellular plasma membranes heme amplifies cellular susceptibility to oxidative-mediated injury by oxidants such as $\mathrm{H}_{2} \mathrm{O}_{2}$ or those derived from activated inflammatory cells (Balla et al., 1991a,b, 1993). Because heme has an atom of $\mathrm{Fe}$ in its structure and can sensitize cellular membranes to $\mathrm{H}_{2} \mathrm{O}_{2}$, it was proposed that heme-induced cytotoxicity could be derived from free radicals generated through the Fenton reaction (Vincent, 1989; Chiu et al., 1996). However, conflicting data makes uncertain that heme can directly catalyze this reaction. Studies using electron paramagnetic resonance $(\mathrm{EPR})$ spin-trapping techniques, in cell free conditions, suggested that neither MetHb (Mao et al., 1994), nor free heme (Van der Zee etal., 1996), can catalyze the Fenton reaction generating hydroxyl radicals. Furthermore, heme induces ROS generation dependent on enzymatic reactions. In fact, it was demonstrated that heme triggers ROS production by the NADPH oxidase enzyme (Graça-Souza et al., 2002; Arruda et al., 2004; Moraes et al., 2012; Barcellos-de-Souza et al., 2013) and by mitochondria (unpublished), through activation of specific signaling pathways (Graça-Souza et al., 2002; Porto et al., 2007; Fernandez et al., 2010; Fortes et al., 2012). Alternatively, hemeinduced formation of radical species relies on the conversion of low-reactive organic hydroperoxides $(\mathrm{ROOH})$ into highly reactive alkoxyl (RO•) and peroxyl (ROO•) radicals (Tappel, 1953, 1955; Van der Zee et al., 1996). These radicals may initiate further lipid peroxidation forming alkyl radicals that in the presence of $\mathrm{O}_{2}$ form more peroxyl radicals leading to a facile propagation of free radical reactions. Ultimately, alkyl radicals are rearranged to form toxic conjugated diens and stimulate the autocatalytic lipid peroxidation cascades (Ryter and Tyrrel, 2000) which could mediate heme-induced toxicity. Together, these data suggest that the cytotoxic heme effects can be mediated by ROS from different sources generated both through non-enzymatic and enzymatic reactions. This leads to at least four possible mechanisms of heme-induced ROS: (1) heme might directly promote ROS generation by the Fe present in its structure through the Fenton reaction, (2) Fe might be released from heme to exert its oxidative effects, (3) heme can activate signaling pathways to induce ROS generation enzymatically, or (4) heme can convert organic hydroperoxides into free radicals.

\section{INFLAMMATORY EFFECTS OF HEME}

Heme activates innate immune cells and non-hematopoietic cells promoting inflammation. Heme injection in mice leads to vascular permeability, leukocyte migration from the intravascular environment to tissues and increase of acute-phase proteins (Lyoumi et al., 1999; Wagener et al., 2001b), hallmarks of acute inflammation. Heme activates endothelial cells inducing the expression of the adhesion molecules ICAM-1 (intercellular adhesion molecule 1), VCAM-1 (vascular cell adhesion molecule 1), E-selectin, Pselectin, and von Willebrand factor (VWF; Wagener et al., 1997; Belcher etal., 2014) and causes neutrophil migration (GraçaSouza et al., 2002; Porto et al., 2007). The adhesion molecules enable neutrophils to attach firmly to the endothelium and migrate to tissues parenchyma. Thus, leukocytes must be activated and 
express adhesion molecules complementary to those expressed by the endothelium. A seminal study demonstrated that the ability of heme to activate neutrophils depend on protein kinase $\mathrm{C}$ (PKC) activation and ROS generation, inducing the expression of adhesion molecules and modifying actin cytoskeleton dynamics, necessary features for neutrophils migration (Graça-Souza et al., 2002). In fact, heme can induce neutrophil migration by acting as a chemotactic molecule (Porto et al., 2007) or by inducing the production of leukotriene B4 (LTB4) by macrophages (Monteiro et al., 2011). Heme-induced neutrophils activation leads to extracellular traps (NETs) release through a mechanism dependent on ROS generation (Chen et al., 2014). Moreover, heme induces the production of the chemokine interleukin (IL)-8 by endothelial cells (Natarajan et al., 2007) and by neutrophils (Graça-Souza etal., 2002). Although neutrophils have important functions controlling infection, these cells can promote vascular and tissue injury by generating ROS, secreting proteases, and releasing extracellular chromatin (NETs; reviewed in Mócsai, 2013). Consequently, the prolonged activity of these cells is detrimental for tissue homeostasis. In this context, heme inhibits neutrophils apoptosis, increasing their longevity, and possibly enhancing harmful stimuli from these cells (Arruda et al., 2004, 2006).

Macrophages stimulate inflammatory responses by secreting cytokines, chemokines, and lipid mediators. TNF, IL-6, and IL-1 $\beta$ are pleiotropic cytokines that regulate cell death, increase vascular endothelial permeability, recruit immune cells to inflamed tissues and induce the production of acute-phase proteins. Part of these effects is mediated by the activation of fibroblasts and endothelial cells, especially by TNF and IL-1 $\beta$. Moreover, IL- $1 \beta$ and TNF modifies the hypothalamus threshold of the body temperature causing fever. KC (keratinocyte-derived chemokine) is a chemokine that attracts neutrophils to sites of inflammation and LTB4 is a lipid mediator that functions as a chemoattractant molecule and also activates leukocytes. Heme activates macrophages inducing the production of TNF, KC (Figueiredo et al., 2007), IL-1 $\beta$ (unpublished), and LTB4 (Monteiro et al., 2011). Although KC and IL-1 $\beta$ functions were not investigated during heme-induced inflammatory effects, TNF and LTB4 were described as essential inflammatory mediators during inflammatory events induced by heme. As described before, LTB4 has an important function regulating heme-induced neutrophils migration (Monteiro et al., 2011). On the other hand, TNF secretion induced by heme is essential for the activation of the programed necrotic cell death pathway, which is denominated necroptosis (Fortes et al., 2012).

Hemoglobin is used as a nutrient by Plasmodium, the protozoan parasite that causes malaria, during its replication stage inside erythrocytes in the course of the infection in mammals (Francis et al., 1997). Hb digestion generates high amounts of free heme which is detoxified by its polymerization into a crystal structure named hemozoin (Hz; Slater et al., 1991; Slater, 1992; Pandey and Tekwani, 1996). Once released from ruptured erythrocytes, $\mathrm{Hz}$ can be phagocytized and accumulated inside macrophages altering their functions. Similarly to heme, $\mathrm{Hz}$ also induces the production of several inflammatory mediators by macrophages such as cytokines and chemokines, and induces leukocytes migration (reviewed by Olivier et al., 2014). In nature, $\mathrm{Hz}$ produced by Plasmodium spp. carries DNA from the parasite. Because DNA is immunogenic and can activate innate immune receptors (Yanai et al., 2009; Coban etal., 2010), the exact role of pure $\mathrm{Hz}$ in the activation of innate immunity is not completely understood (discussed later).

Together, these inflammatory responses triggered by heme indicate that heme is a damage-associated molecular pattern (DAMP), a group of endogenous molecules derived from damaged cells and extracellular matrix degradation capable of promoting and exacerbating immune responses. These concepts challenged the idea that the cytotoxic and inflammatory effects of heme were exclusively mediated by the oxidative capability of the Fe associated with the amphipathic property of the porphyrin ring. Moreover, albeit the controversy about $\mathrm{Hz}$ immunogenicity, $\mathrm{Hz}$ composed of heme and Plasmodium DNA can be defined as a pathogen-associated molecular pattern (PAMP) in the course of malaria infection, promoting inflammation and contributing to pathogenesis.

\section{H0-1 PROTECTION AGAINST HEME}

Plasma scavengers of heme and/or $\mathrm{Hb}$ once saturated allow heme to exert its inflammatory properties. In fact, hemolysis or heme injection in $\mathrm{Hx}^{-/-}$mice cause increased inflammation and severe renal damage compared to wild type (WT) mice (Tolosano et al., 1999; Vinchi et al., 2008). Mice lacking HO-1 (Hmox $\left.1^{-/-}\right)$are highly susceptible to pathologic conditions associated with increased serum heme concentration. For instance, Hmox ${ }^{-/-}$mice develops acute renal failure and marked mortality when submitted to rhabdomyolysis, a pathological condition that increases serum myoglobin which can be oxidized and release heme (Nath et al., 2000). Furthermore, Hmox1-/mice are susceptible to liver IR which is characterized by tissue damage in sites that are reperfused after ischemia injury and hemolysis (Devey et al., 2009). Thus, HO-1 regulation by heme is an essential feedback mechanism that maintains tissue homeostasis through anti-inflammatory and anti-oxidant activities in pathologic situations associated to heme (reviewed by Gozzelino et al., 2010). SCD and $\beta$-thalassemia are genetic diseases associated to erythrocytes that are prone to lysis due to defective $\mathrm{Hb}$ production (Heinle and Read, 1948; Pauling et al., 1949; Ingram, 1957; discussed later). Asymptomatic humans with sickle-cell trait are protected against malaria disease. Interestingly, this fact was suggested to be dependent on heme-induced HO-1 expression. Transgenic sickle-cell hemizygous mice are protected against malaria disease (Ferreira et al., 2011). Besides the fact that these mice do not develop anemia, hemolysis is evidenced by a modest serum heme increase which is sufficient to increase HO-1 expression and CO production (Ferreira et al., 2011). CO inhibits $\mathrm{Hb}$ oxidation and subsequently heme release, thus blocking heme accumulation in serum and preventing heme from exerting its inflammatory effects in the course of malaria disease (Ferreira et al., 2011). This case demonstrates the importance of the feedback production of $\mathrm{HO}-1$ induced by heme to maintain tissue homeostasis. Moreover, heme accumulates in wounded areas and promotes inflammation through the expression of adhesion molecules and the recruitment of leukocytes (Wagener etal., 2003a). During the resolution phase of 
inflammation HO-1 expression in leukocytes reduces adhesion molecules expression and leukocytes migration, thus contributing to wound healing (Wagener et al., 2003a). Although heme is a proinflammatory molecule, the feedback activity of HO-1 inhibits exacerbated inflammation and maintains homeostasis. However, the efficiency of HO-1 to counteract heme depends on the health state of the individual. Heme administration in mice without a genetic or pathologic condition that cause susceptibility to heme might have a therapeutic effect dependent on the activity of HO-1. In fact, heme-induced HO-1 expression prevents injury induced by indomethacin in the intestine (Yoriki et al., 2013), unilateral ureteral obstruction in the kidney (Correa-Costa et al., 2010), nutricional steatohepatitis (Nan et al., 2010), and IR in the liver (Xue et al., 2007).

\section{INNATE IMMUNE RECEPTORS ACTIVATED BY HEME}

The immune system is characterized by the exquisite recognition of exogenous and endogenous molecules, and by its central role in tissue homeostasis as well as contributing to the pathogenesis of several diseases. The physiological consequence of an infection is the activation of an immune response essential to pathogen control or elimination (Medzhitov, 2008). Similarly, sterile tissue damage triggers inflammatory responses fundamental to tissue repair (Nathan and Ding, 2010). For years the mechanism of innate cell activation and function was considered non-specific, in opposition to the ability of $\mathrm{B}$ and $\mathrm{T}$ lymphocytes to recognize antigens by clonal receptors. The specific recognition of molecules from infectious agents and from endogenous origin by innate immune cells is performed by evolutionary conserved membrane and cytosolic receptors also known as pattern recognition receptors (PRRs; reviewed in Takeuchi and Akira, 2010). The presence and function of these receptors on mammals were originally proposed by Janeway (1989) and first confirmed by his group (Medzhitov et al., 1997). PRRs are germline-encoded and represent an essential arm of innate immune cells to sense invading microbes through conserved PAMPs and to detect endogenous stress signals through DAMPs. Several families of innate immune receptors have been described in recent years.

\section{HEME TRANSPORTERS}

For decades it has been appreciated that the transport of nutritional heme across cellular membranes of intestinal epithelial cells is an active and regulated process, more efficient than free Fe transport, requiring energy, and a selective transporter. The molecular nature of mammalian heme transporters remained elusive for many years, in part due to the lack of molecular and genetic tools and also as a consequence of a number of membrane proteins able to bind and transport heme at low affinity. In fact, several transporters of heme and other porphyrins have been described in recent years, although the in vivo importance of some of these molecules on heme trafficking is still object of debate. The cytoplasmic heme importer, named heme carrier protein 1 (HCP1), is expressed in the cytoplasmic membrane of duodenal epithelial cells and is believed to participate on dietary heme absorption (Shayeghi et al., 2005; Latunde-Dada et al., 2006). It was also demonstrated the critical in vivo importance of this putative heme transporter as a mediator of extracellular folate import by intestinal epithelial cells (Qiu et al., 2006). Similarly, the ATP-binding cassette, Abcg2, involved on heme export is also associated with multidrug resistance (Krishnamurthy et al., 2004; Krishnamurthy and Schuetz, 2006). A second exporter of heme is the feline leukemia virus subgroup $\mathrm{C}$ receptor 1 (FLVCR1), in this case the lack of the transporter in mice affects erythroid differentiation and cell survival (Quigley et al., 2004; Keel et al., 2008). A mitochondrial isoform of FLVCR1 named FLVCR1b was recently demonstrated to export heme from the mitochondria to the cytosol (Chiabrando et al., 2012). The heme transporter ATPbinding cassette, Abcb6, controls the translocation of protoporphyrin between the cytosol and the mitochondria (Krishnamurthy et al., 2006). The heme-responsive gene-1 (HRG1) participates in the translocation of heme between the cytosol and endosomal compartments (Rajagopal et al., 2008).

An interesting study demonstrated that heme binds with high affinity to a heme-binding motif present at the intracellular domain of Slo1 channels, and inhibits transmembrane $\mathrm{K}$ currents by decreasing the frequency of channel opening (Tang et al., 2003). This was the first demonstration of an acute signaling effect of heme dependent on a specific transmembrane protein. Heme interactions with these membrane proteins led us to hypothesize that heme activates cells of the innate immune system through binding to an innate immune receptor.

\section{HEME IS AN AGONIST OF TOLL-LIKE RECEPTOR 4}

Using mouse strains deficient in different adaptors and innate immune receptors, we observed that heme-induced TNF production was dependent on MyD88 and Toll-like receptor 4 (TLR4; Figueiredo et al., 2007). TLRs are receptors present in mice and humans, which are distributed among the cellular membrane and intracellular compartments, as endosomes and lysosomes (Takeuchi and Akira, 2010). Each TLR recognize one or more PAMPs derived from different microbes such as bacteria, fungi, parasites, and virus (Takeuchi and Akira, 2010). Besides microbial agonists, TLRs triggers inflammatory responses to endogenous inflammatory molecules. DAMPs that activate TLRs include the high-mobility group box 1 (HMGB1) nuclear protein, myeloidrelated proteins (Mrp8/14), amyloid $\beta$, oxidized LDL (oxLDL), DNA, and RNA in the form of immune complexes, mitochondrial DNA (Oka et al., 2012) and extracellular matrix components such as tenascin-C, fibronectin, and hyaluronan (reviewed by Yu et al., 2010). Other DAMPs such as ATP, formyl peptides, uric acid crystals, and cholesterol crystals activate other innate immune receptors (Mariathasan et al., 2006; Martinon et al., 2006; Duewell et al., 2010; discussed later).

A critical step in characterizing an endogenous molecule as an agonist of an innate immune receptor is the necessity to exclude the presence of any microbial contaminant. In fact, in the case of heat shock proteins (HSPs), the effect on TNF secretion was later attributed to endotoxin contamination in the protein preparations (Gao and Tsan, 2003). Several strategies were used to exclude that the TLR4-induced activation by heme was due to contaminant (Figueiredo et al., 2007). Highly purified heme free of endotoxin contamination was used, as well as polymyxin B, anti-TLR4/MD2, and lipid A antagonist, all of which inhibited 
the effects of LPS but did not interfere with the induction of TNF by heme. Similarly, protoporphyrin IX (PPIX), an antagonist of heme, did not inhibit the activity of LPS on TNF secretion (Figueiredo et al., 2007). The TLR4 engagement by LPS triggers two distinct pathways by the recruitment of the adaptor molecules MyD88 (Muzio et al., 1997; Wesche et al., 1997) and TRIF [TIR (Toll-IL-1 receptor)-domain-containing adapterinducing interferon (IFN)- $\beta$; Hoebe et al., 2003; Yamamoto et al., 2003]. The MyD88-dependent pathway leads to the activation of mitogen-activated protein kinases (MAPKs) and NF-кB (nuclear factor kappa-light-chain-enhancer of activated B cells) transcription factors inducing the expression of inflammatory cytokines such as TNF, IL-6, IL-1 $\beta$, and KC (Takeuchi and Akira, 2010). The TRIF-dependent pathway activates the IRF3 (IFN regulatory transcription factor-3), which induce the expression of type I IFN, and late-phase NF-кB (Takeuchi and Akira, 2010). Heme seems to activate only the MyD88-dependent pathway and is ineffective to induce several cytokines or the expression of costimulatory molecules typical of TLR4 activation by LPS. It can induce MAPK activation and the expression of TNF and KC, but not of IFN $\beta$ or the IFN-dependent gene IP-10 (Figueiredo et al., 2007; Figure 1). Even the transcription of certain MyD88dependent genes is not induced by heme when compared to LPS. In fact, different TLR4 ligands trigger signaling pathways differently. While, monophosphoryl lipid A, an analog of the TLR4 agonist tetra-acylated lipid $\mathrm{A}$, induces a biased response to the TRIF pathway (Mata-Haro et al., 2007), the vesicular stomatitis virus glycoprotein $\mathrm{G}$ induces a biased response to the TRAM pathway to specifically induce IRF7 activation (Georgel et al., 2007). Moreover, human embryonic kidney (HEK) cells transfected with human TLR4 secretes IL-8 upon stimulation with heme (Piazza et al., 2011). In this case, the experiments were performed in the absence of CD-14 and MD-2 transfection.

The differences in signaling pathways activated by different agonists of the TLR4 might be due to (1) a different binding site on the TLR4, compared to LPS, or perhaps (2) the involvement of different co-receptors. (1) Molecular determinants of heme structure for TLR4 activation were determined (Figueiredo et al., 2007). Heme (Fe-PPIX) analogs, porphyrin rings without Fe (PPIX) or with metal substitutions (Pd-PPIX and Sn-PPIX), do not induce TNF production. Fe-mesoporphyrin IX, a heme analog with two ethyl groups substituting its vinyl groups, also is unable to activate TLR4. These data suggests that coordinated Fe and the vinyl groups are necessary for heme effect on TNF production. PPIX functions as an antagonist for TNF production induced by heme but not by LPS (Figueiredo et al., 2007). Conversely, LPS antagonists do not inhibit TNF production induced by heme. Interestingly, the sequence comparison of TLR4 and globins from different species suggests the presence of conserved heme-binding sequences in TLR4 (unpublished). These conserved sequences

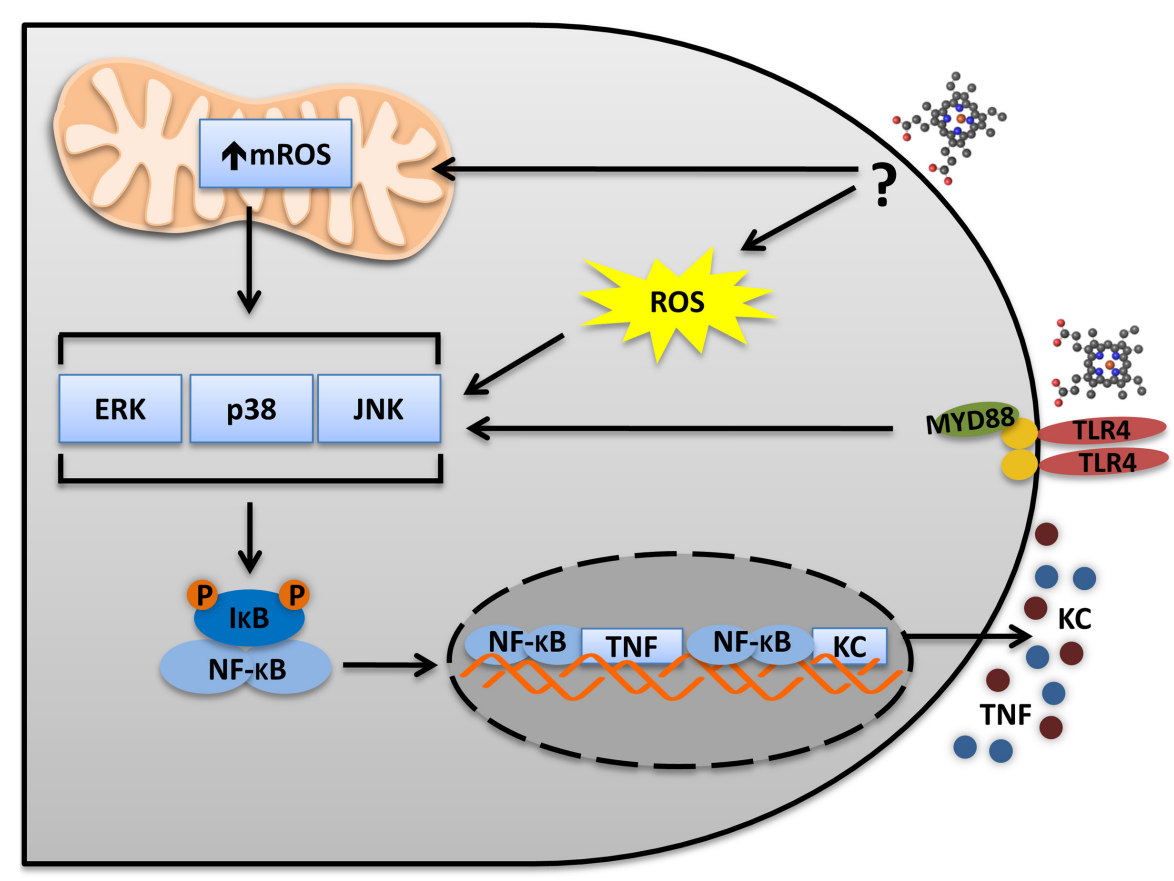

FIGURE 1 | Heme activates TLR4 in macrophages. The TLR4 activates two distinct pathways: MyD88 and TRIF. In macrophages, heme induces a biased MyD88 activation and the secretion of the pro-inflammatory cytokines TNF and KC. TLR4 activation leads to MAPKs and NFKB activation, which are necessary to TNF secretion. Heme induces ROS generation independently of TLR4. However, ROS is necessary to induce TNF secretion and MAPK activation. Thus, TLR4 activation and ROS generation seem to be complementary and both are required for MAPKs and $I_{\kappa} B$ degradation. It will be important to determinate the source of ROS and the mechanisms triggering heme-induced ROS generation. The mitochondria and the NADPH oxidase complexes seem to be involved. mROS scavenger (Mito-TEMPO) and NADPH oxidases inhibitors (apocynin and DPI) block TNF production induced by heme. 
present a histidine which is essential for heme to bind globins. It is tempting to speculate that this histidine is essential for heme induced TLR4 activation. In fact, this same conserved histidine, together with two others non-conserved histidines, was shown to be important for the TLR4 activation induced by nickel in humans cells (Schmidt et al., 2010). The lack of these non-conserved histidines in the murine TLR4 disables the nickel capacity to activate this receptor. Moreover, this conserved histidine is important to Nickel, but not to LPS, to activate the TLR4. (2) Depending on the TLR4 activator, different co-receptors will be involved. LPS depends on MD2 and CD14 to activate TLR4 (Park et al., 2009). Amyloid $\beta$ and oxLDL induce the assembly of a CD36TLR4-TLR6 complex (Stewart et al., 2010), while hyaluronan is recognized by a complex formed by TLR4, MD2, and CD44 (Taylor et al., 2007). Heme depends on CD14 but not MD2 to activate TLR4 and induce TNF (Figueiredo et al., 2007; Piazza et al., 2011).

The crystal structure formed by heme polymerization, $\mathrm{Hz}$, has pro-inflammatory properties dependent on TLR9 activation. However, it is uncertain whether pure $\mathrm{Hz}$ can directly activate TLR9. Because $\mathrm{Hz}$ isolated from $P$. falciparum cellular extract may contain DNA, this might be the TLR9 activator. In fact, it was shown that DNase treatment of Plasmodium $\mathrm{Hz}$ abolishes cytokine production by dendritic cells (DCs; Parroche et al., 2007). However, there is evidence that synthetic $\mathrm{Hz}$, which is free of DNA, induces TLR9-dependent responses in DCs (Coban et al., 2005). Moreover, synthetic $\mathrm{Hz}$ induces conformational changes in recombinant TLR9, similar to those induced by CpG DNA, a well characterized TLR9 agonist (Coban et al., 2010). Interestingly, heme was able to induce similar conformational changes in the recombinant TLR9 (Coban etal., 2010). However, we demonstrated that TLR9 was not involved in heme-induced TNF production because WT and $T / \mathrm{C}^{-/}-$macrophages produce similar amounts of TNF when stimulated with heme (Figueiredo et al., 2007). Moreover, this demonstration suggests that mitochondrial DNA, a TLR9 activator (Oka et al., 2012), is not involved in the production of TNF by heme.

\section{G PROTEIN-COUPLED RECEPTORS}

As mentioned before, heme induces LTB4 production by macrophages to stimulate neutrophil migration in vivo (Monteiro et al., 2011). Surprisingly, heme can also induce neutrophil migration in vitro thus indicating that heme acts as a chemotactic molecule (Graça-Souza etal., 2002; Porto et al., 2007). Chemokines and chemotactic molecules can induce neutrophil migration through $\mathrm{G}$ protein-coupled receptors (GPCR) which are sensitive to pertussis toxin (reviewed in Rot and von Andrian, 2004). Pertussis toxin inhibits heme-induced ROS generation and neutrophil migration, thus suggesting the involvement of a GPCR (Porto et al., 2007). Pharmacological inhibition of several pathways activated by GPCR [PI3K, PKC, phospholipase C (PLC) $\beta$, Rho, p38] demonstrated that ROS generation and neutrophil migration depends on the activation of signaling pathways characteristic of chemotactic receptors (Porto etal., 2007). Interestingly, PI3K and MAPK activation delays neutrophil apoptosis through a NADPH oxidase-dependent mechanism (Graça-Souza etal., 2002). This indicates that similar pathways might be involved in ROS generation, survival, and migratory mechanisms triggered by heme in neutrophils. Furthermore, although several heme analogs were able to induce neutrophil migration, mesoporphyrins, molecules lacking the vinyl groups in their rings, were not chemotactic for neutrophils and selectively inhibited the migration induced by heme (Porto et al., 2007). We believe that mesoporphyrins functions as antagonist molecules blocking the activation of an extracellular receptor. Cytochrome $c$ has a conserved sequence responsible for its interaction with heme. This same sequence is present in the Slol channel and was proved to be essential for its binding to heme (Tang etal., 2003). Interestingly, we found this conserved sequence in two chemotactic receptors expressed in neutrophils. Together, these results raises the possibility that heme activates neutrophils through the activation of a GPCR.

\section{MECHANISMS INVOLVED IN HEME-INDUCED CELL DEATH AND INFLAMMATION CYTOTOXIC EFFECTS CONTROLLED BY SPECIFIC SIGNALING PATHWAYS}

Because of its lipid intercalating ability, heme was assumed to induce its cytotoxic and inflammatory effects mediated by its pro-oxidant and amphipathic properties. However, new possibilities emerged because of the new characterized mechanisms of inflammatory responses induced by heme. Heme activates TLR4 to induce cytokine production and necrotic cell death (Figueiredo et al., 2007; Fortes et al., 2012; Figure 2). Hemeinduced necrosis depends on TNF produced by TLR4 activation, because $T l 4^{-/}$and $\mathrm{Tnfr}^{-/-}$macrophages are resistant to the cytotoxic effects of heme (Fortes et al., 2012). However, heme sensitizes Tlr4 ${ }^{-/-}$macrophages to TNF-induced cell death, indicating that TLR4 is essential to heme-induced TNF production, but not directly required for the cell death induced by heme. The necrotic cell death induced by heme was dependent on ROS generation, since antioxidants prevented it (Fortes et al., 2012). Moreover, Rip $1^{-/-}$and Rip3 $3^{-/-}$cells were resistant to heme-induced necrotic cell death (Fortes et al., 2012), characterizing the type of programed cell death as necroptosis (Cho et al., 2009; He et al., 2009; Zhang et al., 2009). Interestingly, ROS induction is essential but not sufficient to cause cell death. In fact, TLR4 and TNFR deletions do not change the capacity of heme to induce ROS generation (Figueiredo et al., 2007). Therefore, it is clear that heme triggers ROS-induced sensitization of macrophages to TNFR-mediated cell death through RIP1 and RIP3 activation to promote necroptosis (Figure 2). Moreover, inhibition of Jun N-terminal kinase (JNK) also decreases heme-induced ROS and necroptosis (Fortes et al., 2012; Figure 2). Heme-induced necroptosis is reversed by deferoxamine, a Fe chelator. Fe can mediate non-enzymatic ROS generation by the Fenton reaction. However, since deferoxamine binds to heme (Baysal et al., 1990; Lu etal., 2012), we cannot exclude the possibility that its inhibitory effect is directly related to heme and not to free Fe. In fact, the protective effect of pharmacologic inhibition of NADPH oxidase and mitochondrial ROS (mROS) on hemeinduced TNF and macrophage necroptosis suggests that enzymatic ROS production is essential for the cytotoxic effects of heme (unpublished). 


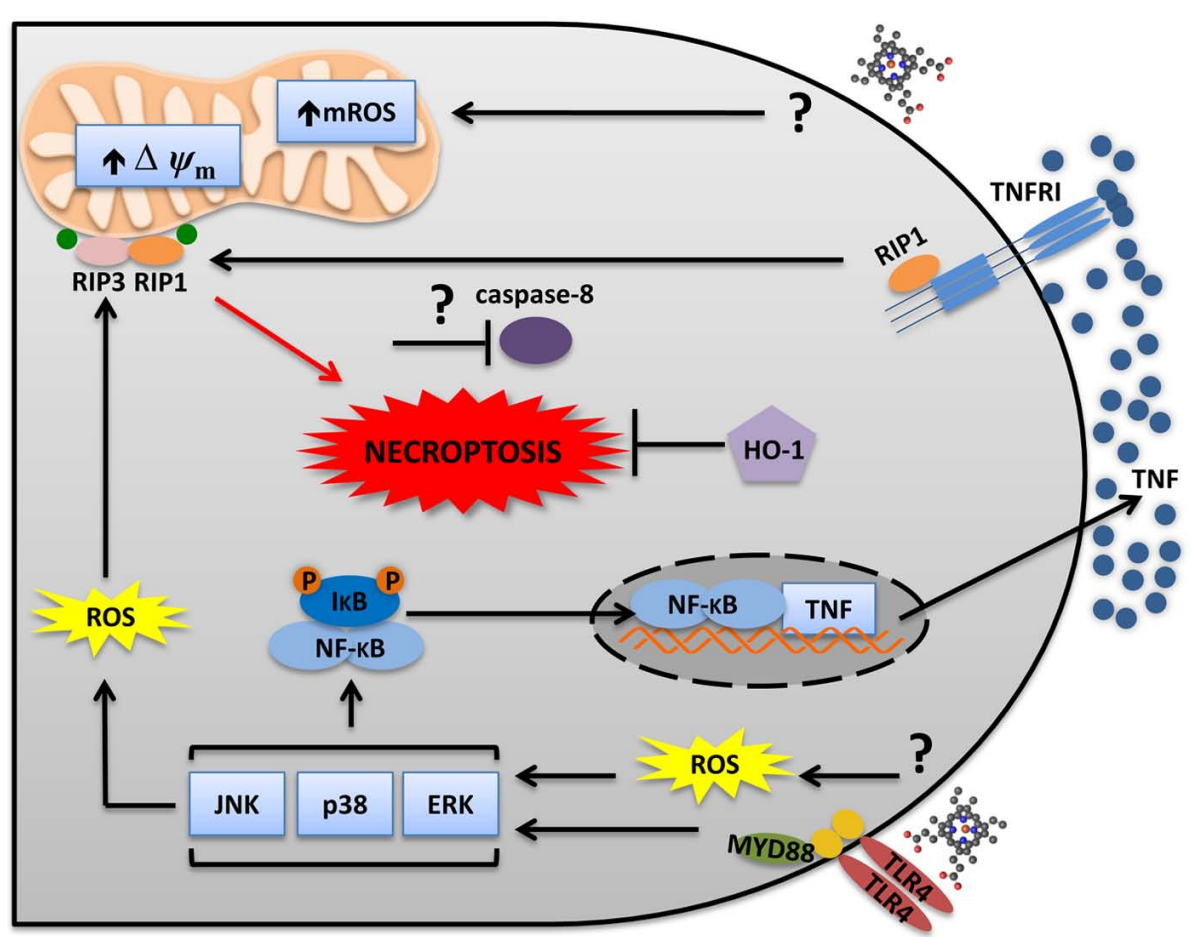

FIGURE 2 | Heme induces RIP1/RIP3-dependent programed cell death. Heme triggers two distinct but integrated pathways to promote necroptosis. Heme induces ROS generation independently of TLR4. ROS sensitizes macrophages to TNFR-induced cell death. Heme-induced TLR4 activation leads to MAPKs activation and TNF production. While JNK increases ROS generation, TNF induces RIP1-RIP3 necrosome which triggers necroptosis.
The mitochondria and the NADPH oxidase complexes seem to be involved. mROS scavenger (Mito-TEMPO) and NADPH oxidases inhibitors (apocynin and DPI) block heme-induced necroptosis. Necroptosis only develops when caspases are inhibited. However, it is not known if heme requires caspase inhibition to induce necroptosis. Moreover, $\mathrm{HO}-1$ has a protective effect during heme-induced necroptosis.
Heme also induces programed cell death in non-hematopoietic cells. Stimulation of astrocytes with heme, as a model of hemorrhagic injury, causes cell death with characteristics of programed necrosis including the loss of plasma membrane integrity, reversion by necrostatin-1, a selective inhibitor of RIP1, and by antioxidants (Laird et al., 2008). Extracellular-signal-regulated kinase (ERK) activation is also involved in astrocyte cell death induced by heme (Regan et al., 2001). Interestingly, heme-induced ERK activation in these cells is ROS-independent (Regan et al., 2001) indicating the involvement of a distinct pathway that might involve TLR4 signaling. In fact, TLR4 is involved in intracerebral hemorrhage (ICH) induced by heme (Lin et al., 2012). Microglia cells, another cell type present in the central nervous system, undergoes cell death through heme-induced activation of JNK and p38 (Cai et al., 2011). Moreover, heme induces apoptosis in human brain vascular endothelial cells (HBVEC) by STAT3 (signal transducer and activator of transcription 3)-dependent activation of matrix metallopeptidase 3 (MMP3; Liu et al., 2013). Heme also sensitizes other non-hematopoietic cells to TNF-induced cell death (Seixas et al., 2009; Larsen et al., 2010; Sukumari-Ramesh et al., 2010; Gozzelino et al., 2012). This cell death has morphological and biochemical characteristics of apoptosis including caspase activation, membrane blebbing, nuclear shrinking, and fragmentation, as well as chromatin condensation and formation of apoptotic bodies (Seixas et al., 2009). Treatment with antioxidants, increased expression of $\mathrm{HO}-1$ or $\mathrm{Hx}$ also revert the heme/TNF-induced cell death in hepatocytes (Seixas et al., 2009; Gozzelino et al., 2010, 2012; Larsen et al., 2010; Gozzelino and Soares, 2011).

Heme induces $\mathrm{HO}-1$ that in turn protects cells from death (Vile et al., 1994; Poss and Tonegawa, 1997a; Ferris et al., 1999; Brouard et al., 2002; Arruda et al., 2004; Seixas et al., 2009; Gozzelino et al., 2010; Kovtunovych et al., 2010; Larsen et al., 2010). The ability of HO- 1 to promote cytoprotection has been attributed to its role controlling heme amounts as well as Fe homeostasis and oxidative stress (Gozzelino et al., 2010). Mice lacking HO-1 (Hmox1-/-) has Fe overload, increase cell death and widespread inflammation (Poss and Tonegawa, 1997a,b; Kovtunovych et al., 2010). In vitro embryonic fibroblasts from $\mathrm{Hmox}^{-/-}$mice are more sensitive to heme or $\mathrm{H}_{2} \mathrm{O}_{2}$ and present increase oxidative stress (Poss and Tonegawa, 1997a). Moreover, $H m o x 1^{-/-}$mice have reduced macrophage numbers in the spleen and liver due to cell death (Kovtunovych et al., 2010). This increased macrophage cell death was confirmed in vitro upon erythrophagocytosis, further suggesting that the in vivo exposure to heme is the cause of the increased macrophage death observed in $H \operatorname{mox} 1^{-1}-$ mice. This result is corroborated by the increased necroptosis observed in $H m o x 1^{-/-}$ macrophages exposed to heme compared to WT (Fortes et al., 2012). Treatment with antioxidants fully blocked heme-induced cell death of $\mathrm{Hmox}_{\mathrm{I}} \mathrm{I}^{-}$macrophages. 
Importantly, increased expression of $\mathrm{FtH}$ also protects different cell types from the cytotoxic effects of heme, TNF or heme and TNF (Balla et al., 1992; Berberat et al., 2003; Cozzi et al., 2003; Gozzelino et al., 2012). These results suggest that Fe derived from heme catabolism participates in the heme-induced sensitization to cell death. The mechanism depends on the sustained activation of JNK induced by Fe-derived ROS. The increased JNK activation inhibits FtH expression, increasing the amount of labile $\mathrm{Fe}$ and consequently the amounts of ROS. The antioxidant property of FtH blocks TNF-induced JNK activation, reducing cell death (Pham et al., 2004; Kamata et al., 2005; Gozzelino et al., 2012). Thus, it seems that JNK activation is a common trigger of hemeinduced cell death in a variety of cells (macrophages, hepatocytes, and microglia; Figure 2). Thus heme induces programed cell death in different types of cells by the regulation of specific signaling pathways.

\section{THE SPLEEN TYROSINE KINASE PATHWAY OF INFLAMMATION}

The cytotoxic effect of heme has important impact in different pathological conditions. This is in part due to the loss of essential tissue functions and in part due to the release of cellular contents with inflammatory activities. High amounts of free heme are found in infectious diseases, such as malaria and sepsis (Pamplona et al., 2007; Larsen et al., 2010), suggesting that heme can amplify inflammatory responses during infection. In fact, it was demonstrated that dying hepatocytes release HMGB1 upon heme and TNF challenge, which in turn increases the systemic inflammatory response (Larsen et al., 2010). Another mechanism involved in heme-induced inflammation during infectious conditions is the amplification of cytokine production induced by heme with microbial molecules. Hb synergizes with LPS enhancing the production of pro-inflammatory cytokines by macrophages (Yang et al., 2002). The opposite effect of globin indicates that heme moiety is the responsible for the potentiating effect of Hb. A low dose of LPS on its own that causes an insignificant cytokine secretion, together with heme results in substantial production of cytokines, thus suggesting that this synergism may be particularly important under conditions of low agonist concentrations, helping the control of infectious agents (Fernandez et al., 2010). This amplification response can also be deleterious under higher concentrations of heme and microbial molecules. In vivo, injection of heme and LPS induces a significant increase in the concentrations of TNF and IL- 6 when compared to the challenge with LPS alone (Fernandez et al., 2010). Moreover, the co-injection of non-lethal doses of heme and LPS induces 100\% lethality.

Interestingly, although purified $\mathrm{Hx}$ inhibits the synergy between heme and PAMPs, the synergy only occurs in the presence of serum, a condition that protects the cells against heme-induced TLR4-dependent TNF production and necroptosis. Heme synergizes with ligands of TLR2, TLR3, TLR4, TLR9, NOD1 (nucleotide-binding oligomerization domain 1), and NOD2 to increase TNF and IL-6 production by macrophages (Figure 3). The synergy between heme and LPS, a TLR4 activator, is induced by the enhanced activation of MAPKs (ERK, p38, JNK) and NF-кB (Fernandez et al., 2010; Figure 3). The mechanism depends on spleen tyrosine kinase (Syk) phosphorylation which regulates the
ROS production induced by heme (Figure 3). Heme-induced Syk phosphorylation modulates ROS generation by activating PKC and calcium signaling through PLC $\gamma$, two downstream molecules regulated by Syk, which are involved in the synergy between heme and LPS (Fernandez et al., 2010). In fact, Syk modulates signaling pathways activated by TLRs cytokine production by macrophages and DC (Brown et al., 2003; Gantner et al., 2003; Turnbull etal., 2005). Syk is a signaling molecule activated by receptors that signal through immunoreceptor tyrosine-based activation motifs (ITAMs) suggesting the involvement of a receptor in the synergy between heme and PAMPs (Underhill and Goodridge, 2007; Figure 3). On the other hand, Syk is also activated independently of cell surface receptors by disturbances in lipid rafts domains ( $\mathrm{Ng}$ et al., 2008; Figure 3). Because of heme's capacity to intercalate cellular membranes we cannot exclude the possibility that Syk might be activated by the direct contact of heme with cellular membranes. It will be important to investigate whether heme-induced Syk phosphorylation requires a receptor.

\section{THE NLRP3 INFLAMMASOME}

While TNF and IL- 6 are mainly regulated at the transcriptional and translational levels, cytokines such as IL- $1 \beta$ and IL-18 requires two steps to be produced. These cytokines are expressed as zymogens, pro-IL-1 $\beta$ and pro-IL-18, which are regulated by the synthesis of their mRNA by TLRs. However, IL- $1 \beta$ and IL-18 maturation requires cleavage of their zymogens by caspase-1 (Cerretti et al., 1992; Thornberry et al., 1992), which is activated independently of TLR signaling. The cleavage of these pro-forms is necessary for their biological effects. Caspase-1 is activated by a multienzymatic platform called the inflammasome, which is composed of NLRs (NOD-like receptors), ASC (apoptosis-associated speck-like protein), and caspase-1 (Martinon et al., 2002; Wen et al., 2013). NLRP3 (nucleotide-binding domain, leucine rich family, pyrin containing 3 gene) is the best characterized inflammasome receptor and is activated by several DAMPs such as ATP, Hz, amyloid $\beta$, uric acid crystals, and cholesterol crystals (Mariathasan et al., 2006; Martinon et al., 2006; Halle et al., 2008; Shio et al., 2009; Duewell et al., 2010; mechanisms reviewed in Latz et al., 2013). Three mechanisms are involved in the NLRP3 inflammasome activation: $\mathrm{K}^{+}$ efflux (Petrilli et al., 2007; Muñoz-Planillo et al., 2013), lysosome damage (Hornung et al., 2008), and mitochondrial dysfunctions that lead to mROS generation (Zhou et al., 2011) and the release of cardiolipin (Iyer et al., 2013) and mitochondrial DNA (Shimada et al., 2012).

In this context, we found that heme induces IL- $1 \beta$ production by activated LPS-primed macrophages promoting NLRP3dependent processing of IL-1 $\beta$ (unpublished). Although heme is capable of activating TLR 4 , it does not induce IL- $1 \beta$ expression (Figueiredo et al., 2007). Heme (Fe-PPIX), but not its analogs, porphyrin rings without Fe (PPIX) or with metal substitutions (Pd-PPIX and Sn-PPIX), induces IL-1 $\beta$ processing and release (unpublished). The activation of NLRP3 by heme required $\mathrm{K}^{+}$ efflux, Syk phosphorylation, mROS, and NOX2. On the other hand, the mechanism was independent of ATP release and lysosomal damage (unpublished). Our results are in sharp contrast with a recent published report that describes the ability of heme to 


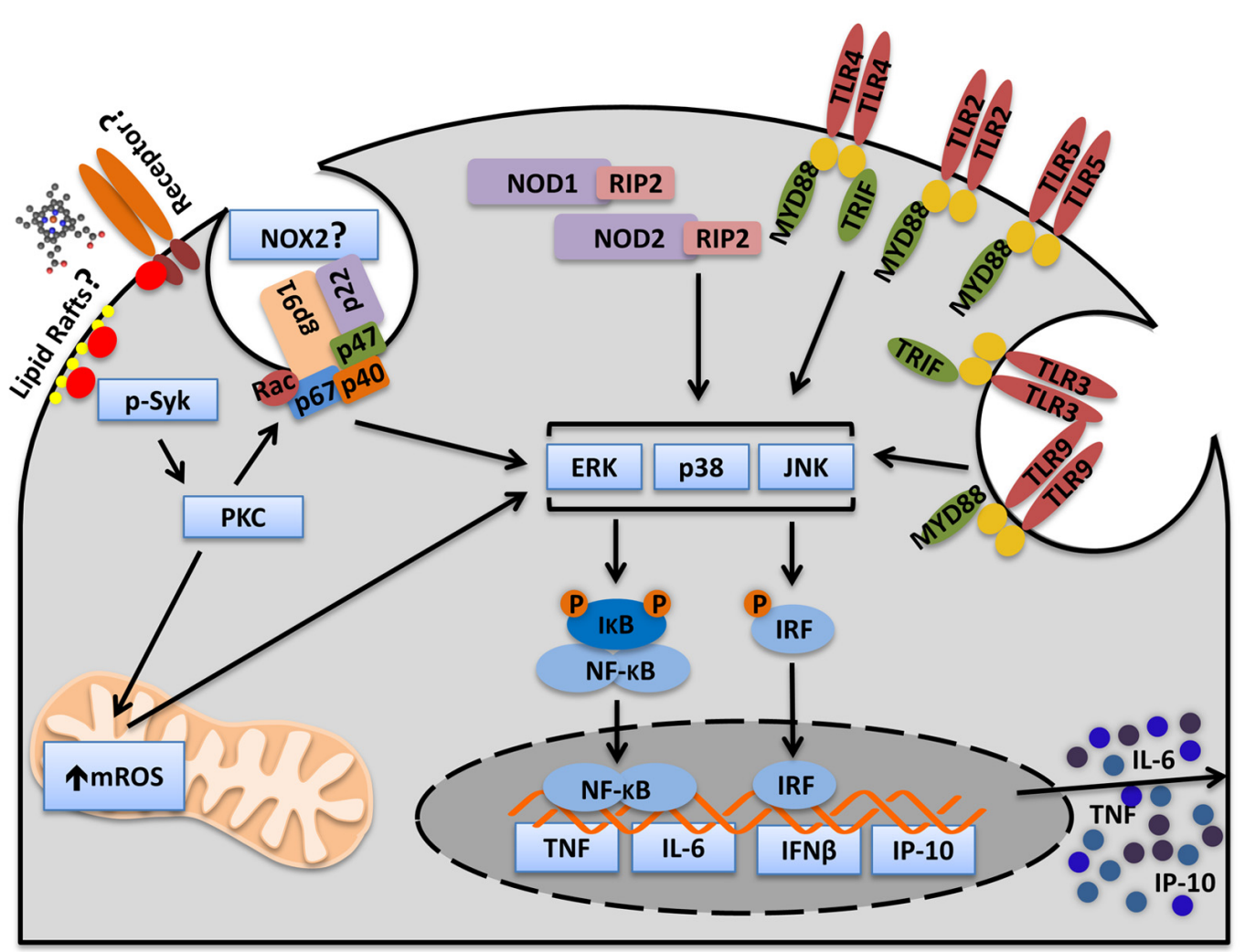

FIGURE 3 | Heme activates Syk and amplifies cytokine production induced by PAMPs. Heme induces Syk phosphorylation in macrophages. The Syk pathway is essential for heme-induced ROS production. Heme-induced ROS generation increases MAPKs and NFKB activation and consequently, cytokine production. Heme amplifies cytokines induced by cell surface receptors (TLR2, TLR4, TLR5), endosome receptors (TLR3, TLR9), and cytosolic receptors (NOD1 and NOD2). Moreover, heme amplifies MyD88(TNF and IL-6) and TRIF-dependent (IP-10) cytokines. The mechanism by which heme triggers Syk activation is not known. However, there are two possibilities. Heme could trigger Syk activation through an unknown surface receptor or through interaction with lipid rafts. The source of ROS controlled by Syk is not known but because PKC, NOX, and mitochondria inhibitors blocks the synergism between heme and PAMPs it is possible to consider that Syk controls ROS generation by NOX and mitochondria. Although NOX2 is the principal NADPH oxidase complex in phagocytes we cannot exclude the possibility that other NOX might be involved. activate the NLRP3 inflammasome (Li et al., 2014). (1) Heme and PPIX caused the maturation of IL- $1 \beta$ in the absence of serum ( $\mathrm{Li}$ et al., 2014). In our experimental conditions, heme did not activate the inflammasome in the absence of serum (unpublished). This same result was previously published (Dostert et al., 2009). Interestingly, the synergism of heme with PAMPs regarding the production of TNF and IL-6 is also dependent on serum (Fernandez et al., 2010; Lin et al., 2010). The reason why heme requires serum to induce part of its inflammatory effects needs further investigation. (2) Heme and PPIX primed the macrophages and induced IL-1 $\beta$ mRNA expression (Li et al., 2014). It is possible that the procedure to elicit peritoneal macrophages used in their study primed the cells for subsequent inflammasome activation. We observed that PPIX did not induce pro-IL-1 $\beta$ or inflammasome activation, suggesting that the iron in the porphyrin ring is essential for the effect of heme (unpublished). (3) Heme-induced IL- $1 \beta$ secretion depended on P2X receptors (Li etal., 2014). This observation suggests that ATP release is involved. In fact, ATP release from necrotic cells activates NLRP3 (Iyer et al., 2009). Importantly, their experimental procedure was made without serum. This could have increased the cell death of macrophages stimulated with heme and the subsequent released of ATP. Differently from their results, we demonstrated that heme induced similar amounts of IL-1 $\beta$ in WT and P2X7-deficient macrophages (unpublished). Moreover, the use of oxidized ATP (ATP antagonist) and apyrase (degrades ATP) corroborate that heme-induced inflammasome activation is independent of ATP (unpublished).

One of the mechanisms responsible for the NLRP3 activation involves the phagocytosis of crystal structures, subsequent lysosome damage and cathepsin B release to the cytosol (Hornung etal., 2008). In fact, phagocytosis and cathepsin $\mathrm{B}$ inhibition blocks the inflammasome activation induced by crystals, including $\mathrm{Hz}$ (Shio et al., 2009). Like heme, $\mathrm{Hz}$ also depends on ROS generation and Syk phosphorylation to activate NLRP3 (Shio etal., 2009). Heme, on the other hand, does not require phagocytosis or lysosome damage to induce IL-1 $\beta$ secretion (unpublished). Thus, heme activates the NLRP3 inflammasome with a distinct mechanism compared to ATP and $\mathrm{Hz}$. 
In vivo, heme injection induced IL- $1 \beta$ production and caspase1-dependent neutrophil migration in mice peritoneum (unpublished). Moreover, Caspase- $1^{-/-}$mice were resistant to mortality induced by hemolysis. On the other hand, heme can be used to prevent inflammation through the induction of HO-1. In fact, preventive induction of HO-1 induced by heme inhibits the NLRP3 inflammasome activation in the liver (Kim and Lee, 2013) and the lung (Luo etal., 2014) in different pathological conditions.

\section{POSSIBLE ROLES OF HEME-INDUCED INNATE IMMUNE RECEPTOR ACTIVATION ON PATHOGENESIS SICKLE CELL DISEASE AND $\beta$-THALASSEMIA}

Pathologies associated with intravascular hemolysis are the most commonly related to heme inflammatory effects. SCD and $\beta$-thalassemia are molecular blood disorders caused by mutations in genes encoding $\mathrm{Hb}$ (Heinle and Read, 1948; Pauling et al., 1949; Ingram, 1957). In SCD, a single point mutation in the $\mathrm{Hb}$ gene encodes a protein that polymerizes under low-oxygen conditions causing red blood cells (RBC) deformation (sickle shape; Edelstein et al., 1973; Browne et al., 1998). Repeated sickling episodes decrease RBC elasticity rendering them susceptible to hemolysis (Hebbel, 1991). $\beta$-Thalassemia is the result of a mutation in the $\beta$-globin chain gene that impairs the $\beta$-globin chain production and leads to accumulation of the $\alpha$-globin which can aggregate causing hemolysis and erythroid precursor premature death (Khandros et al., 2012). Chronic episodes of hemolyses increase the concentrations of $\mathrm{Hb}$ and heme which are considered to be the major responsible for vascular inflammation in these diseases (Muller-Eberhard et al., 1968; Chies and Nardi, 2001; Figure 4). In fact, hematin injection in healthy volunteers induces thrombophlebitis and disturbed homeostasis (Simionatto et al., 1988). Moreover, polymorphisms in the promoter region of the Hmoxl gene is associated with decreased rates of hospitalization of patients with acute chest syndrome (ACS; Bean et al., 2012), a major life-threatening condition for patients with SCD (Gladwin and Vichinsky, 2008). Repeated vaso-occlusion episodes are characteristic of SCD and can lead to tissue damage due to IR (Kaul and Hebbel, 2000; Figure 4). Heme induces the expression of adhesion molecules in the vasculature (Wagener et al., 1997, 2001a; Belcher et al., 2014). The adherence of leukocytes and reticulocytes to the endothelium causes stasis and painful crisis, a hallmark of SCD pathogenesis (Belcher et al., 2000). $\beta$-thalassemic patients also experience signs of vascular inflammation and vasoocclusion due to endothelial adhesion of aggregated thalassemic erythrocytes and reduced NO bioavailability (Bunyaratvej et al., 1995; Hovav et al., 1999; Hahalis et al., 2008). In this disease, cardiac complications seem to be the main cause of mortality (Engle et al., 1964; Spirito and Maron, 1990).

Transgenic SCD mice present typical signs of multiorgan pathology and vascular inflammation such as oxidative stress, endothelial activation, and reduced NO bioavailability (Pászty etal., 1997; Ryan etal., 1997; Belcher etal., 2003). Also, $\beta$-thalassemic mice present the same signs of vasculopathy (Vinchi et al., 2013). This phenotype is similar to that of $H x^{-/-}$mice during hemolysis or heme overload (Tolosano et al., 1999; Vinchi et al., 2008). In both models, vascular inflammation was associated with an increase is serum heme concentration and Hx depletion. This fact is also observed in patients with hemolytic anemia (Muller-Eberhard et al., 1968; Adisa et al., 2013). Hx administration protects transgenic SCD mice and $\beta$-thalassemic mice from heme-induced oxidative stress and vascular inflammation (Vinchi et al., 2013). Hx works by chelating and delivering heme to the liver where it is catabolized by HO-1. In this context, Hx-heme complex-induced HO- 1 protects the liver against heme cytotoxic effects (Vinchi et al., 2013). The increased HO-1 expression reduces vascular inflammation, vaso-occlusion and liver damage (Belcher et al., 2000; Vinchi et al., 2008, 2013). While Hx treatment protects SCD mice with severe respiratory symptoms from acute lung inflammation (ALI; Ghosh et al., 2013) and SCD mice from stasis (Belcher et al., 2014), Hx also improves cardiovascular functions in $\beta$-thalassemic mice (Vinchi etal., 2013).

Recent studies demonstrated that heme-induced endothelial cell activation is at least in part mediated by TLR4 signaling. Heme-induced TLR4 activation in endothelial cells leads to NF- $\kappa \mathrm{B}$ activation, adhesion molecules expression and WeibelPalade body degranulation (Belcher et al., 2014), which contains the VWF and P-selectins, molecules involved in SCD vasculopathy (Matsui et al., 2001; Chen et al., 2011a; Figure 4). Blockade of adhesion molecules, including VWF and P-selectin, inhibits heme-induced stasis in SCD mice (Belcher et al., 2014). TLR4 is also involved in heme-induced ACS. The TLR4 specific antagonist, TAK-242, which inhibits TLR4 signaling by the intracellular domain, protects transgenic SCD mice from heme-induced stasis and ACS (Ghosh et al., 2013; Belcher et al., 2014). In fact, Tlr4-/mice or TAK-242 administration prevented ALI and respiratory distress induced by heme (Ghosh et al., 2013). These results suggest that TLR4 could be a new therapeutic target for treating SCD.

Furthermore, antioxidants proved to be efficient modulators of vascular functions in hemolytic diseases. In fact, PKC inhibition and antioxidants also protects transgenic SCD mice from hemeinduced stasis (Belcher et al., 2014). PKC was shown to mediate heme-induced ROS generation in macrophages by the Syk pathway and in neutrophils by a signaling pathway characteristic of a GPCR (Porto et al., 2007; Fernandez et al., 2010). Because ROS generation induced by heme is TLR4-independent (Figueiredo et al., 2007), it is possible that another receptor might collaborate with TLR4 to promote vascular inflammation.

Another possible mechanism involved in the pathogenesis of SCD is the release of NETs by neutrophils (Chen et al., 2014). NETs are fibers composed of chromatin (DNA and histones) decorated with antimicrobial peptides. In contrast to its functions in host defense against pathogens, which NET exert by trapping and killing them, exaggerated NET formation is implicated in a number of pathologies (reviewed by Zawrotniak and Rapala-Kozik, 2013). In this context, NET formation has been shown to contribute to disseminated intravascular coagulation in the course of inflammatory diseases and therefore to morbidity and mortality in sepsis (Fuchs et al., 2010; Massberg et al., 2010; von Bruhl et al., 2012). Thus, this effect could contribute to vaso-occlusion and ACS in the course of SCD. In fact, patients with SCD presented NET formation in plasma during steady state conditions, 


\section{(1) Hemolysis due to: (2) Endothelial (3) Vaso-occlusion (4) Hypoxia and SCD or $\beta$-thalassemia Neutrophil Tissue injury activation}

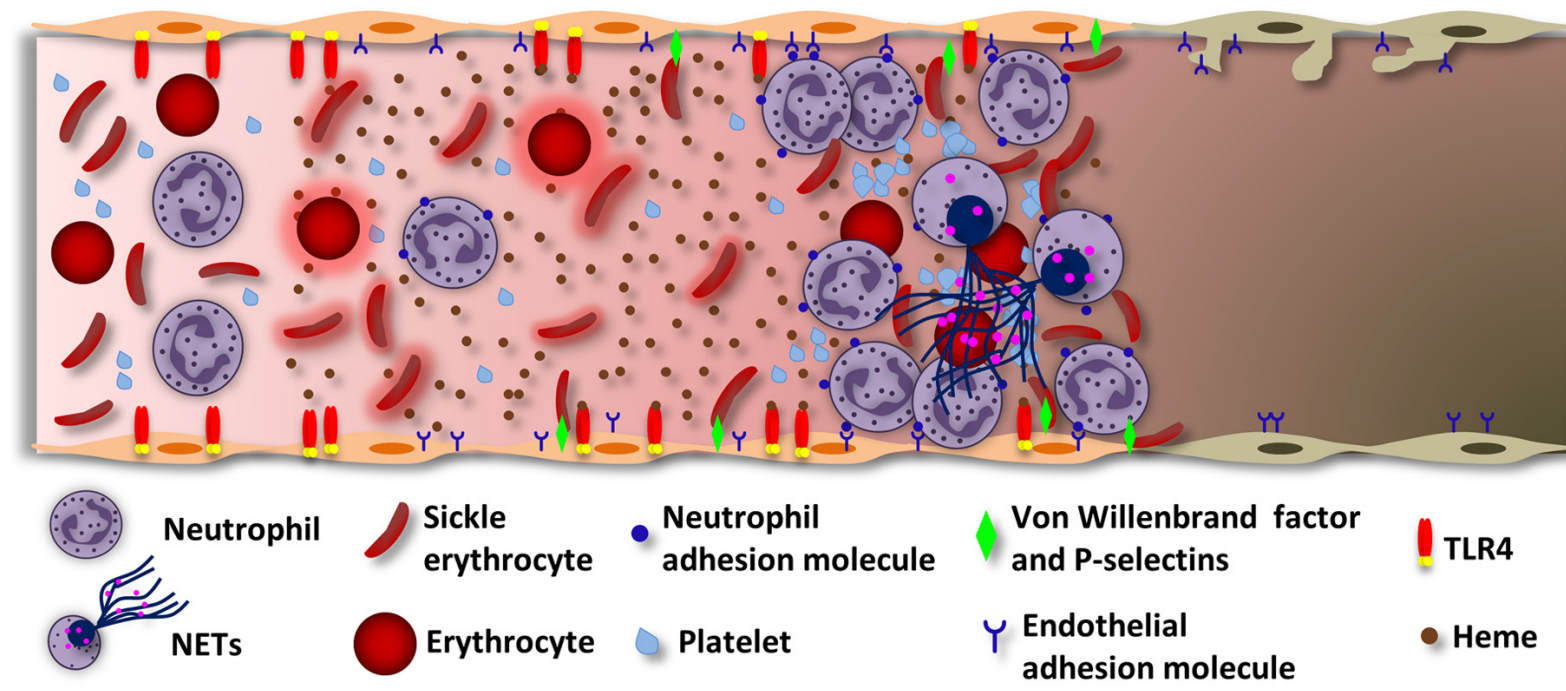

FIGURE 4 | Heme induces vascular inflammation in hemolytic diseases. During intravascular hemolysis the serum proteins responsible for removing heme get saturated and heme can exert its inflammatory effects. (1) Hemolysis can happen due to ischemia/reperfusion, SCD or $\beta$-thalassemia. While in SCD, Hb polymerization alters erythrocytes physically, in $\beta$-thalassemia the accumulation of $\alpha$-globin aggregates inside the erythrocytes. In both cases, the erythrocytes became more susceptible to hemolysis. Hemolysis increases the concentration of $\mathrm{Hb}$ which, under oxidative stress, releases free heme. (2) Heme activates neutrophils and endothelial cells, by ROS generation. In both cells, heme induces the expression of complementary adhesion molecules. In endothelial cells, heme induces TLR4-dependent degranulation of Weibel-Palade bodies and P-selectins and VWF release. The VWF is prothrombotic and can increase the adhesion of erythrocytes to the endothelium. Heme also induces the expression of the adhesion molecules ICAM-1, VCAM-1, and E-selectins. Neutrophils stimulated by heme and TNF releases NETs. (3) These events lead to the adhesion of neutrophils to endothelial cells. The activated endothelium now expresses molecules that can interact with surface molecules localized in erythrocytes. Also, erythrocytes express molecules that can interact with platelets. Together, these events lead to vaso-occlusion. (4) Depending on the extension of the vaso-occlusion, some tissues may experience hypoxia and damage. Vaso-occlusion of the lung microvasculature may result in the development of the ACS through the infarction of the lung parenchyma. Heme-induced TLR4 activation in endothelial cells and NETs release contribute to the ACS. when compared to healthy individuals (Schimmel et al., 2013). The amount of NET formation was increased during painful crisis and ACS, and correlated with the length of hospitalization. Moreover, TNF administration in SCD mice induced NET formation within the pulmonary microvasculature (Chen et al., 2014). DNAse I treatment prevented lung inflammation and vascular permeability induced by TNF in SCD mice. In this study heme was reported to mediate NET formation in SCD mice. In vitro, TNFprimed neutrophils released NETs after the stimulation with heme. Furthermore, Hx treatment prevented TNF-induced NET formation and hypothermia in SCD mice demonstrating an important role for heme in the induction of NET formation in this model. Together, these data suggest that heme-induced NET formation might contribute to the pathogenesis of SCD (Figure 4).

\section{ATYPICAL UREMIC HEMOLYTIC SYNDROME}

Atypical hemolytic uremic syndrome (aHUS) is characterized by an over activation of the complement alternative pathway (CAP) due to genetic and acquired abnormalities (Noris and Remuzzi, 2009). The pathogenesis of this disease involves glomerular endothelial damage, leukocyte activation, thrombotic microangiopathy (blood clots in small blood vessels), and mechanical hemolysis. However, the observed mutations are insufficient to induce complement abnormal activation requiring a triggering stimulus for disease manifestation. A broad range of precipitating events is related with aHUS including infections, drugs, autoimmune conditions, transplants, pregnancy, and metabolic conditions (reviewed in Loirat and Fremeaux-Bacchi, 2011). It was suggested that heme derived from hemolysis could act as a secondary hit capable of amplifying aHUS pathogenesis (deCiutiis et al., 1978; Mold et al., 1995; Ruiz-Torres et al., 2005; Pawluczkowycz etal., 2007). In fact, heme activates the CAP in the serum and on endothelial cells surfaces (Frimat etal., 2013). This effect is enhanced by mutations associated to CAP overactivation during aHUS. Heme-induced exocytosis of WeibelPalade bodies from endothelial cells induces the expression of P-selectins in the plasma membrane, which are known to bind the complement $\mathrm{C} 3 \mathrm{~b}$ protein and trigger CAP activation, and to release the prothrombotic VWF (Frimat et al., 2013). Moreover, heme induces the release of $\mathrm{C} 5 \mathrm{a}$ and $\mathrm{C} 5 \mathrm{~b} 9$, fragments of the C5 complement protein known to induce endothelial cell activation and permeabilization. Thus the combined effect of heme-induced CAP and TLR4 activation in endothelial cells (Frimat et al., 2013; Belcher et al., 2014) may act together to induce 
Weibel-Palade body degranulation, contributing to renal damage in aHUS.

\section{INTRACEREBRAL HEMORRHAGE}

Intracerebral hemorrhage is a bleeding into the brain parenchyma. Although the mass effect of an edema derived from an expanding hematoma mediates part of the brain injury, there are evidences pointing inflammation and cytotoxic degradation products of blood as mediators of ICH injury (Xi et al., 2006). While Hx injection protects brain tissues from rat cerebral IR (Dong et al., 2013), $H x^{-/-}$mice are susceptible to ICH (Chen et al., 2011b) suggesting a role for free heme in this process. In fact, bleeding will result in hemolysis and free heme release. Depending on experimental conditions, HO-1 can be deleterious or beneficial in neurodegenerative models. Interestingly, in a mouse model of $\mathrm{ICH}, \mathrm{Hmox}^{-/-}$ mice present reduced brain damage (Wang and Doré, 2007) suggesting that cerebral cells are prone to the oxidative effects of free Fe derived from heme catabolism. In fact, the treatment with the $\mathrm{Fe}$ chelator deferoxamine ameliorates brain injury after ICH or subarachnoid hemorrhage (Gu et al., 2009; Lee et al., 2010; Chen et al., 2011c).

TLR4 has been involved in brain injury during ICH (Teng etal., 2009; Sansing etal., 2011; Fang etal., 2013; Wang etal., 2013). Exogenous heme induces brain injury through TLR4induced inflammation (Lin et al., 2012). In fact, $\mathrm{Tlr}^{-/-}$or anti-TLR4 treatment suppresses heme-induced neuroinflammation, edema, and neurologic deficit. Moreover, heme activates microglia cells to produce TNF, IL- 6 , and IL- $1 \beta$ through TLR4 signaling indicating that heme can directly activate brain cells (Lin et al., 2012). Heme-induced IL-1 $\beta$ production during neuroinflammation suggests the involvement of the NLRP3 inflammasome. In macrophages, heme induces IL- $1 \beta$ secretion via mROS generation and NLRP3 activation (Li et al., 2014; unpublished data). Interestingly, NLRP3 knockdown and mROS inhibitors reduce brain edema and improve neurological functions (Ma et al., 2014).

\section{ATHEROGENESIS}

Atherosclerosis is a chronic inflammatory disease characterized by the formation of plaques in the vessel walls (Libby etal., 2002). Plaque formation is initiated by lipid accumulation in subendothelial spaces and metabolic dysfunction in infiltrating monocyte-derived macrophages which contributes to foam cells development (Moore and Tabas, 2011). Part of these cells die and release their fat and cholesterol-laden membranes into the intercellular space recruiting more monocytes in a chronic process that increases the formation of the necrotic core (Guyton and Klemp, 1996; Virmani et al., 2005). The necrotic core rupture can lead to serious complications. The release of plaque components into the blood stream form clots that damages the heart muscle and slowly develop ischemic heart disease (Falk et al., 1995; Arroyo and Lee, 1999). Also, if these clots are big enough they can block blood flow and induce tissue necrosis. On the other hand, the necrotic core rupture exposes inflammatory components which can bind platelet cells at the rupture site and induce their accumulation forming thrombus which can be large enough to produce vessel lumen narrowing (Virmani et al., 2005).
Low-density lipoprotein is the major lipid involved in plaque formation. In the inflammatory environment, subendothelial LDL is oxidized and becomes a potent inflammatory molecule. oxLDL activates intraplaque macrophages by the TLR4-TLR6CD36 complex engagement leading to the activation of the NFKB pro-inflammatory pathway and facilitating endocytosis (Stewart et al., 2010). oxLDL endocytosis leads to the formation of crystalline substances inside lysosomes causing the destabilization of this organelle as well the release of proteases, events that lead to the NLRP3 inflammasome activation (Duewell et al., 2010). Indeed, TLRs and NLRP3 have been associated with atherosclerosis development.

Low-density lipoprotein oxidation and its inflammatory effects can be enhanced by the development of new vessels inside the necrotic core (Virmani etal., 2005). The major stimulus for this angiogenic process seems to be hypoxia (Bjornheden et al., 1999; Sluimer et al., 2008). In fact, the plaque atheroma composition decreases oxygen availability rendering the necrotic core structure a hypoxic condition. Furthermore, inflammatory cells can actively contribute to angiogenesis by secretion of angiogenic factors, such as vascular endothelial growth factor (VEGF), fibroblast growth factor 2 (FGF2), and plateletderived growth factor BB (PDGFBB) ligands (Cheng et al., 2013). The new vessels generally arise from vasa vasorum (Kwon et al., 1998), a network of small blood vessels that supply the walls of large blood vessels. Plaque new vessels are immature and present a fragile structure which is prone to leakage and highly vulnerable to rupture, thus causing intraplaque hemorrhage (Kolodgie etal., 2003; Dunmore et al., 2007; Sluimer et al., 2009). This event is responsible for increased entry of erythrocytes and inflammatory cells inside the necrotic core. Erythrocytes that enter developing atherosclerosis lesions are prone to lysis by lipid oxidation products. Erythrocytes lysis increases the amount of extracellular $\mathrm{Hb}$ which in a highly oxidative environment leads to MetHb formation and the release of free heme. LDL oxidation induced by heme increases the oxidation of lipids and inflammatory stimuli, contributing to further plaque development (Balla et al., 1991a). In fact, hemeinduced LDL oxidation is highly cytotoxic for endothelial cells and LDL oxidation seems to be mediated by Fe (Jeney et al., 2002; Nagy etal., 2010). This group of events, triggered by plaque hemorrhage, increases plaque vulnerability and consequently raises the risk of thrombus formation and ischemic heart disease (Michel et al., 2011). Expression of HO-1 provides protection against several cardiovascular diseases, including atherosclerosis (reviewed by $\mathrm{Wu}$ et al., 2011). Interestingly, a 6-year-old patient with HO-1 deficiency experienced a severe atherosclerotic pathology (Yachie et al., 1999). This patient suffered from persistent intravascular hemolysis, anemia, endothelial damage, iron deposition, and cellular sensibility to heme cytotoxic effects. These observations resemble those of $\mathrm{Hmox}^{-/-}$ mice, thus demonstrating the importance of $\mathrm{HO}-1$ functions in the maintenance of iron recycling and tissue homeostasis.

After hemolysis, sustained interaction between $\mathrm{Hb}$ and ROS can lead to ferrylhemoglobin (ferrylHb) formation, which is characterized by an increase in the $\mathrm{Fe}$ oxidative state to $\mathrm{Fe}^{+4}$ 
(Harel and Kanner, 1988; Patel et al., 1996). ferrylHb undergoes intermolecular cross-linking of its globin chains forming aggregates, which induces the expression of adhesion molecules in vascular endothelial cells that support the recruitment of macrophages into the vessel wall (Silva et al., 2009; Potor et al., 2013). Similarly to heme, ferrylHb activates endothelial cells through NFKB activation (Silva et al., 2009). However, the mechanism responsible for NFKB activation is different. While TLR4 and ROS mediate heme-induced activation of macrophages and endothelial cells (Figueiredo et al., 2007; Belcher et al., 2014), ferrylHb activates endothelial cells independently of TLR4 and ROS (Silva et al., 2009). Moreover, ferrylHb is unable to induce cytokine secretion by endothelial cells (Silva et al., 2009), another difference to heme which induces IL-8 production (Natarajan et al., 2007). Like MetHb, ferrylHb is unstable and releases free heme to further increase oxLDL formation (Potor et al., 2013). Thus, heme and ferrylHb can induce direct effects, such as endothelial cells activation, and indirect effects, like LDL oxidation to increase atheroma plaque development and atherosclerosis pathogenesis.

Besides heme pro-inflammatory capacity in atherosclerotic plaque development, it was proposed that heme could mediate an atheroprotective event. Recently, heme was shown to activate human monocytes by the induction of activating transcription factor 1 (ATF-1), coupling the expression of $\mathrm{HO}-1$ and liver $\mathrm{X}$ receptor (LXR)- $\beta$ to induce a specific macrophage phenotype (Boyle etal., 2012). HO-1 is well known for its homeostatic functions creating an antioxidant and cytoprotective environment against heme and Fe deleterious effects (Gozzelino et al., 2010). LXR- $\beta$ protects against lipid overload by activating a lipid exportation program regulated by proteins such as LXR- $\alpha$ and ATP binding cassette transporter A1 (ABCA1), preventing foam cells formation. This phenotype induced by heme is distinct from M1, M2, and Mox (reviewed in Moore et al., 2013) and therefore was named Mhem. Mhem was described in macrophages from atheroma plaques of patients with fatal coronary artery disease (Boyle et al., 2009). In this context, ATF-1 is able to convert macrophages to an atheroprotective state coordinating Fe and lipid metabolism.

The Mhem phenotype contrasts with the Fe-loaded M1 macrophages phenotype which presents an enhanced production of TNF and hydroxyl radicals, and has the capacity to induce precocious fibroblast senescence, impairing wound healing (Sindrilaru etal., 2011). Macrophages with this phenotype were described in the skin of patients with chronic venous leg ulcers (CVUs). This disease is caused by chronic venous valve insufficiency that leads to hypertension in the lower-limb veins, with persistent erythrocyte extravasation. Erythrophagocytosis by tissue macrophages and release of heme-bound Fe seems to be the trigger of this pro-inflammatory phenotype. It will be interesting to investigate the presence of Mhem in other pathologies such CVUs to understand the environments and factors involved in the development of Mhem and its capacity to modulate proinflammatory microenvironments also induced by heme and Fe. Moreover, it will be interesting to characterize the putative involvement of innate immune receptors activated by heme in these processes.

\section{HEMOLYSIS DUE TO INFECTION}

Vascular hemolysis is a relevant factor in some infectious diseases. The severe pathology observed in malaria and hemorrhagic fevers is a result of complex events that triggers a vigorous inflammatory response. The systemic inflammatory response and the disseminated intravascular coagulation observed in severe cases of these diseases are similar to septic shock and are also dependent on the production of high amounts of inflammatory mediators such as TNF, IL-6, and IL-1 $\beta$. Heme homeostasis is critically involved in the development of sepsis and malaria (Pamplona et al., 2007; Larsen et al., 2010; Gozzelino et al., 2012). In both cases it is possible to observe high amounts of heme in the circulation (Figure 4). In malaria, it was demonstrated that heme acts together with high amounts of ROS to induce the disruption of the blood-brain barrier permitting the migration of inflammatory cells, plasmatic proteins, and Plasmodium antigens, which cause damage to brain tissues (Pamplona et al., 2007). In the CLP (cecal ligation and puncture) model of sepsis, heme sensitizes hepatocytes to necrotic cell death rendering mice more susceptible to sepsis (Larsen et al., 2010). Moreover, there is a negative correlation between $\mathrm{Hx}$ serum concentration and tissue damage in patients with septic shock. Therefore, patients with septic shock presenting higher serum concentrations of $\mathrm{Hx}$ develop decreased tissue damage and have a better survival outcome, suggesting an important role for heme during sepsis (Larsen et al., 2010). As discussed, Hx inhibits several pro-inflammatory effects induced by heme such as ROS generation, cell death (Larsen et al., 2010; Gozzelino et al., 2012), and the synergistic effect (Lin et al., 2010) with PAMPs. HO-1 has a central role in maintaining tissues homeostasis against heme noxious effects, since Hmox ${ }^{-1-}$ mice are extremely susceptible to CLP and cerebral malaria (Pamplona et al., 2007; Larsen et al., 2010). In both cases, HO-1 maintains tissue homeostasis independently of parasite burden. Thus, HO-1 confers tolerance against these infectious diseases. On the other hand, HO- 1 induction confers host resistance, rather than tolerance, to Mycobacterium infection (Silva-Gomes et al., 2013). Hmox1-/- mice infected with M. avium presented a susceptible phenotype with an increased pathogen burden due to impaired protective granuloma formation. HO1 deficiency induced heme accumulation and macrophage cell death which contributed to M. avium proliferation. In fact, heme administration to macrophages in vitro increased M. avium proliferation and heme injection in infected mice prevented granuloma formation. Moreover, Hmox1-/- mice infected with M. tuberculosis died while WT and heterozygous mice (Hmox1+/-) survived. Thus, HO-1 plays a critical role during Mycobacterium infection by preventing heme-induced granuloma macrophage death and bacterial proliferation. Besides its role in tissue tolerance and bacterial control, HO- 1 antioxidant activity might contribute to intracellular bacterial multiplication. In fact, HO-1 impairs resistance to Plasmodium infection in the liver (Epiphanio et al., 2008) and to non-typhoid Salmonella (NTS), a common complication of P. falciparum infection (Cunnington et al., 2012a,b). In fact, hemolysis triggered by Plasmodium infection causes premature mobilization of bone-marrow granulocytes with impaired antioxidant defenses due to $\mathrm{HO}-1$ expression (Cunnington et al., 2012a,b). This leads to uncontrolled bacterial load and lethal bacteremia. Together these observations reinforce the concept that 
heme might be used as a target for adjuvant therapies during infectious diseases.

\section{FUTURE PERSPECTIVES}

The last 10 years of research on heme inflammatory properties brought new insights to understand its functions in hemolytic and hemorrhagic pathologies. Besides the fact that heme presents direct cytotoxic properties, it is now clear that heme can activate specific receptors and signaling pathways to promote ROS generation, inflammation, and programed cell death. Important studies demonstrated that heme-induced TLR4 activation is involved in the pathogenesis of SCD and ICH. Interestingly, a specific inhibitor of TLR4 signaling is very efficient preventing heme-induced vasculopathy and lung injury in mouse models of these diseases. Moreover, heme activates the NLRP3 inflammasome inducing IL- $\beta$ processing and secretion. The critical role of the inflammasome in the pathological response following lethal hemolysis was unveiled. Moreover, new studies are helping to understand the beneficial properties of heme scavenging proteins such as $\mathrm{Hx}$. In fact, $\mathrm{Hx}$ was shown to protect mice against infectious (malaria and sepsis) and non-infectious (SCD, $\beta$-thalassemia, and cerebral IR) models of diseases. Characterizing the role of cell death pathways induced by heme and the participation of heme transporters on hemolytic diseases promises interesting perspectives. Thus, understanding the molecular signaling pathways affected by heme might prove useful to the identification of new options for treating pathological conditions that course with increased extracellular heme and inflammation.

\section{ACKNOWLEDGMENTS}

We thank Miriam Werneck for critical reading of the manuscript. Marcelo T. Bozza received financial support from Conselho Nacional de Pesquisa (CNPq), Fundação de Amparo à Pesquisa do Estado do Rio de Janeiro (FAPERJ), and INCT Dengue, Brazil. Fabianno F. Dutra has a postdoctoral fellowship from Programa Nacional de Pós-Doutorado (PNPD) CAPES/FAPERJ.

\section{REFERENCES}

Adisa, O. A., Hu, Y., Ghosh, S., Aryee, D., Osunkwo, I., and Ofori-Acquah, S. F. (2013). Association between plasma free haem and incidence of vaso-occlusive episodes and acute chest syndrome in children with sickle cell disease. $\mathrm{Br} . J$. Haematol. 162, 702-705. doi: 10.1111/bjh.12445

Aft, R. L., and Mueller, G. C. (1983). Hemin-mediated DNA strand scission. J. Biol. Chem. 258, 12069-12072.

Aft, R. L., and Mueller, G. C. (1984). Hemin-mediated oxidative degradation of proteins. J. Biol. Chem. 259, 301-305.

Arosio, P., Ingrassia, R., and Cavadini, P. (2009). Ferritins: a family of molecules for iron storage, antioxidation and more. Biochim. Biophys. Acta 1790, 589-599. doi: 10.1016/j.bbagen.2008.09.004

Arroyo, L. H., and Lee, R. T. (1999). Mechanisms of plaque rupture: mechanical and biologic interactions. Cardiovasc. Res. 41, 369-375. doi: 10.1016/S00086363(98)00308-3

Arruda, M. A., Barcellos-de-Souza, P., Sampaio, A. L., Rossi, A. G., Graca-Souza, A. V., and Barja-Fidalgo, C. (2006). NADPH oxidase-derived ROS: key modulators of heme-induced mitochondrial stability in human neutrophils. Exp. Cell Res. 312, 3939-3948. doi: 10.1016/j.yexcr.2006.08.022

Arruda, M. A., Rossi, A. G., de Freitas, M. S., Barja-Fidalgo, C., and Graca-Souza, A. V. (2004). Heme inhibits human neutrophil apoptosis: involvement of phosphoinositide 3-kinase, MAPK, and NF-kappaB. J. Immunol. 173, 2023-2030. doi: 10.4049/jimmunol.173.3.2023
Balla, G., Jacob, H. S., Balla, J., Rosenberg, M., Nath, K., Apple, F., et al. (1992). Ferritin: a cytoprotective antioxidant strategem of endothelium. J. Biol. Chem. 267, 18148-18153.

Balla, G., Jacob, H. S., Eaton, J. W., Belcher, J. D., and Vercellotti, G. M. (1991a). Hemin: a possible physiological mediator of low density lipoprotein oxidation and endothelial injury. Arterioscler. Thromb. 11, 1700-1711. doi: 10.1161/01.ATV.11.6.1700

Balla, G., Vercellotti, G. M., Muller-Eberhard, U., Eaton, J., and Jacob, H. S. (1991b). Exposure of endothelial cells to free heme potentiates damage mediated by granulocytes and toxic oxygen species. Lab. Invest. 64, 648-655.

Balla, J., Jacob, H. S., Balla, G., Nath, K., Eaton, J. W., and Vercellotti, G. M. (1993). Endothelial-cell heme uptake from heme proteins: induction of sensitization and desensitization to oxidant damage. Proc. Natl. Acad. Sci. U.S.A. 90, 9285-9289. doi: 10.1073/pnas.90.20.9285

Baranano, D. E., Rao, M., Ferris, C. D., and Snyder, S. H. (2002). Biliverdin reductase: a major physiologic cytoprotectant. Proc. Natl. Acad. Sci. U.S.A. 99, 16093-16098. doi: 10.1073/pnas.252626999

Barcellos-de-Souza, P., Moraes, J. A., de-Freitas-Junior, J. C., Morgado-Diaz, J. A., Barja-Fidalgo, C., and Arruda, M. A. (2013). Heme modulates intestinal epithelial cell activation: involvement of NADPHox-derived ROS signaling. Am. J. Physiol. Cell Physiol. 304, C170-C179. doi: 10.1152/ajpcell.00078.2012

Baysal, E., Monteiro, H. P., Sullivan, S. G., and Stern, A. (1990). Desferrioxamine protects human red blood cells from hemin-induced hemolysis. Free Radic. Biol. Med. 9, 5-10. doi: 10.1016/0891-5849(90)90043-I

Bean, C. J., Boulet, S. L., Ellingsen, D., Pyle, M. E., Barron-Casella, E. A., Casella, J. F., et al. (2012). Heme oxygenase-1 gene promoter polymorphism is associated with reduced incidence of acute chest syndrome among children with sickle cell disease. Blood 120, 3822-3828. doi: 10.1182/blood-2011-06-361642

Belcher, J. D., Bryant, C. J., Nguyen, J., Bowlin, P. R., Kielbik, M. C., Bischof, J. C., et al. (2003). Transgenic sickle mice have vascular inflammation. Blood 101, 3953-3959. doi: 10.1182/blood-2002-10-3313

Belcher, J. D., Chen, C., Nguyen, J., Milbauer, L., Abdulla, F., Alayash, A. I., et al. (2014). Heme triggers TLR4 signaling leading to endothelial cell activation and vaso-occlusion in murine sickle cell disease. Blood 123, 377-390. doi: 10.1182/blood-2013-04-495887

Belcher, J. D., Marker, P. H., Weber, J. P., Hebbel, R. P., and Vercellotti, G. M. (2000). Activated monocytes in sickle cell disease: potential role in the activation of vascular endothelium and vaso-occlusion. Blood 96, 2451-2459.

Berberat, P. O., Katori, M., Kaczmarek, E., Anselmo, D., Lassman, C., Ke, B., et al. (2003). Heavy chain ferritin acts as an antiapoptotic gene that protects livers from ischemia reperfusion injury. FASEB J. 17, 1724-1726.

Bjornheden, T., Levin, M., Evaldsson, M., and Wiklund, O. (1999). Evidence of hypoxic areas within the arterial wall in vivo. Arterioscler. Thromb. Vasc. Biol. 19, 870-876. doi: 10.1161/01.ATV.19.4.870

Boyle, J. J., Harrington, H. A., Piper, E., Elderfield, K., Stark, J., Landis, R. C., et al. (2009). Coronary intraplaque hemorrhage evokes a novel atheroprotective macrophage phenotype. Am. J. Pathol. 174, 1097-1108. doi: 10.2353/ajpath.2009.080431

Boyle, J. J., Johns, M., Kampfer, T., Nguyen, A. T., Game, L., Schaer, D. J., et al. (2012). Activating transcription factor 1 directs Mhem atheroprotective macrophages through coordinated iron handling and foam cell protection. Circ. Res. 110, 20-33. doi: 10.1161/CIRCRESAHA.111.247577

Brouard, S., Berberat, P. O., Tobiasch, E., Seldon, M. P., Bach, F. H., and Soares, M. P. (2002). Heme oxygenase-1-derived carbon monoxide requires the activation of transcription factor NF-kappa B to protect endothelial cells from tumor necrosis factor-alpha-mediated apoptosis. J. Biol. Chem. 277, 17950-17961. doi: 10.1074/jbc.M108317200

Brown, G. D., Herre, J., Williams, D. L., Willment, J. A., Marshall, A. S., and Gordon, S. (2003). Dectin-1 mediates the biological effects of beta-glucans. J. Exp. Med. 197, 1119-1124. doi: 10.1084/jem.20021890

Browne, P., Shalev, O., and Hebbel, R. P. (1998). The molecular pathobiology of cell membrane iron: the sickle red cell as a model. Free Radic. Biol. Med. 24, 1040-1048. doi: 10.1016/S0891-5849(97)00391-2

Broxmeyer, H. E., Cooper, S., Levi, S., and Arosio, P. (1991). Mutated recombinant human heavy-chain ferritins and myelosuppression in vitro and in vivo: a link between ferritin ferroxidase activity and biological function. Proc. Natl. Acad. Sci. U.S.A. 88, 770-774. doi: 10.1073/pnas.88.3.770

Bunyaratvej, A., Fucharoen, S., Butthep, P., Sae-ung, N., Kamchonwongpaisan, S., and Khuhapinant, A. (1995). Alterations and pathology of thalassemic red cells: 
comparison between alpha- and beta-thalassemia. Southeast Asian J. Trop. Med. Public Health. 26(Suppl. 1), 257-260.

Cai, Y., Cho, G. S., Ju, C., Wang, S. L., Ryu, J. H., Shin, C. Y., et al. (2011). Activated microglia are less vulnerable to hemin toxicity due to nitric oxide-dependent inhibition of JNK and p38 MAPK activation. J. Immunol. 187, 1314-1321. doi: 10.4049/jimmunol.1002925

Cerretti, D. P., Kozlosky, C. J., Mosley, B., Nelson, N., Van Ness, K., Greenstreet, T. A., et al. (1992). Molecular cloning of the interleukin-1 beta converting enzyme. Science 256, 97-100. doi: 10.1126/science.1373520

Chen, G., Zhang, D., Fuchs, T. A., Wagner, D. D., and Frenette, P. S. (2014). Hemeinduced neutrophil extracellular traps contribute to the pathogenesis of sickle cell disease. Blood doi: 10.1182/blood-2013-10-529982 [Epub ahead of print].

Chen, J., Hobbs, W. E., Le, J., Lenting, P. J., de Groot, P. G., and Lopez, J. A. (2011a). The rate of hemolysis in sickle cell disease correlates with the quantity of active von Willebrand factor in the plasma. Blood 117, 3680-3683. doi: 10.1182/blood2010-08-302539

Chen, L., Zhang, X., Chen-Roetling, J., and Regan, R. F. (2011b). Increased striatal injury and behavioral deficits after intracerebral hemorrhage in hemopexin knockout mice. J. Neurosurg. 114, 1159-1167. doi: 10.3171/2010.10.JNS10861

Chen, Z., Gao, C., Hua, Y., Keep, R. F., Muraszko, K., and Xi, G. (2011c). Role of iron in brain injury after intraventricular hemorrhage. Stroke 42, 465-470. doi: 10.1161/STROKEAHA.110.602755

Cheng, C., Chrifi, I., Pasterkamp, G., and Duckers, H. J. (2013). Biological mechanisms of microvessel formation in advanced atherosclerosis: the big five. Trends Cardiovasc Med. 23, 153-164. doi: 10.1016/j.tcm.2012.10.004

Chiabrando, D., Marro, S., Mercurio, S., Giorgi, C., Petrillo, S., Vinchi, F., et al. (2012). The mitochondrial heme exporter FLVCR1b mediates erythroid differentiation. J. Clin. Invest. 122, 4569-4579. doi: 10.1172/JCI62422

Chies, J. A., and Nardi, N. B. (2001). Sickle cell disease: a chronic inflammatory condition. Med. Hypotheses 57, 46-50. doi: 10.1054/mehy.2000.1310

Chiu, D., and Lubin, B. (1989). Oxidative hemoglobin denaturation and RBC destruction: the effect of heme on red cell membranes. Semin. Hematol. 26, 128-135.

Chiu, D. T., van den Berg, J., Kuypers, F. A., Hung, I. J., Wei, J. S., and Liu, T. Z. (1996). Correlation of membrane lipid peroxidation with oxidation of hemoglobin variants: possibly related to the rates of hemin release. Free Radic. Biol. Med. 21, 89-95. doi: 10.1016/0891-5849(96)00035-4

Cho, Y. S., Challa, S., Moquin, D., Genga, R., Ray, T. D., Guildford, M., et al. (2009). Phosphorylation-driven assembly of the RIP1-RIP3 complex regulates programmed necrosis and virus-induced inflammation. Cell 137, 1112-1123. doi: 10.1016/j.cell.2009.05.037

Coban, C., Igari, Y., Yagi, M., Reimer, T., Koyama, S., Aoshi, T., et al. (2010). Immunogenicity of whole-parasite vaccines against Plasmodium falciparum involves malarial hemozoin and host TLR9. Cell Host Microbe 7, 50-61. doi: 10.1016/j.chom.2009.12.003

Coban, C., Ishii, K. J., Kawai, T., Hemmi, H., Sato, S., Uematsu, S., et al. (2005). Toll-like receptor 9 mediates innate immune activation by the malaria pigment hemozoin. J. Exp. Med. 201, 19-25. doi: 10.1084/jem.20041836

Correa-Costa, M., Semedo, P., Monteiro, A. P., Silva, R. C., Pereira, R. L., Goncalves, G. M., etal. (2010). Induction of heme oxygenase-1 can halt and even reverse renal tubule-interstitial fibrosis. PLOS ONE 5:e14298. doi: 10.1371/journal.pone.0014298

Cozzi, A., Levi, S., Corsi, B., Santambrogio, P., Campanella, A., Gerardi, G., et al. (2003). Role of iron and ferritin in TNFalpha-induced apoptosis in HeLa cells. FEBS Lett. 537, 187-192. doi: 10.1016/S0014-5793(03)00114-5

Cunnington, A. J., de Souza, J. B., Walther, M., and Riley, E. M. (2012a). Malaria impairs resistance to Salmonella through heme- and heme oxygenasedependent dysfunctional granulocyte mobilization. Nat Med. 18, 120-127. doi: $10.1038 / \mathrm{nm} .2601$

Cunnington, A. J., Njie, M., Correa, S., Takem, E. N., Riley, E. M., and Walther, M. (2012b). Prolonged neutrophil dysfunction after Plasmodium falciparum malaria is related to hemolysis and heme oxygenase-1 induction. J. Immunol. 189, 53365346. doi: 10.4049/jimmunol.1201028

Dawson, J. H. (1988). Probing structure-function relations in heme-containing oxygenases and peroxidases. Science 240, 433-439. doi: 10.1126/science.3358128

deCiutiis, A. C., Peterson, C. M., Polley, M. J., and Metakis, L. J. (1978). Alternative pathway activation in sickle cell disease and beta-thalassemia major. J. Natl. Med. Assoc. 70, 503-506.
Devey, L., Ferenbach, D., Mohr, E., Sangster, K., Bellamy, C. O., Hughes, J., et al. (2009). Tissue-resident macrophages protect the liver from ischemia reperfusion injury via a heme oxygenase-1-dependent mechanism. Mol. Ther. 17, 65-72. doi: 10.1038/mt.2008.237

Dong, B., Cai, M., Fang, Z., Wei, H., Zhu, F., Li, G., et al. (2013). Hemopexin induces neuroprotection in the rat subjected to focal cerebral ischemia. BMC Neurosci. 14:58. doi: 10.1186/1471-2202-14-58

Dostert, C., Guarda, G., Romero, J. F., Menu, P., Gross, O., Tardivel, A., et al. (2009). Malarial hemozoin is a Nalp3 inflammasome activating danger signal. PLoS ONE 4:e6510. doi: 10.1371/journal.pone.0006510

Duewell, P., Kono, H., Rayner, K. J., Sirois, C. M., Vladimer, G., Bauernfeind, F. G., et al. (2010). NLRP3 inflammasomes are required for atherogenesis and activated by cholesterol crystals. Nature 464, 1357-1361. doi: 10.1038/nature 08938

Dunmore, B. J., McCarthy, M. J., Naylor, A. R., and Brindle, N. P. (2007). Carotid plaque instability and ischemic symptoms are linked to immaturity of microvessels within plaques. J. Vasc. Surg. 45, 155-159. doi: 10.1016/j.jvs.2006.08.072

Edelstein, S. J., Telford, J. N., and Crepeau, R. H. (1973). Structure of fibers of sickle cell hemoglobin. Proc. Natl. Acad. Sci. U.S.A. 70, 1104-1107. doi: 10.1073/pnas.70.4.1104

Eisenstein, R. S., Garcia-Mayol, D., Pettingell, W., and Munro, H. N. (1991). Regulation of ferritin and heme oxygenase synthesis in rat fibroblasts by different forms of iron. Proc. Natl. Acad. Sci. U.S.A. 88, 688-692. doi: 10.1073/pnas.88.3.688

Engle, M. A., Erlandson, M., and Smith, C. H. (1964). Late cardiac complications of chronic, severe, refractory anemia with hemochromatosis. Circulation 30, 698705. doi: 10.1161/01.CIR.30.5.698

Epiphanio, S., Mikolajczak, S. A., Goncalves, L. A., Pamplona, A., Portugal, S., Albuquerque, S., et al. (2008). Heme oxygenase-1 is an anti-inflammatory host factor that promotes murine plasmodium liver infection. Cell Host Microbe 3, 331-338. doi: 10.1016/j.chom.2008.04.003

Eskew, J. D., Vanacore, R. M., Sung, L., Morales, P. J., and Smith, A. (1999). Cellular protection mechanisms against extracellular heme. heme-hemopexin, but not free heme, activates the N-terminal c-jun kinase. J. Biol. Chem. 274, 638-648. doi: 10.1074/jbc.274.2.638

Evans, S. V., and Brayer, G. D. (1988). Horse heart metmyoglobin. A 2.8-A resolution three-dimensional structure determination. J. Biol. Chem. 263, 4263-4268.

Falk, E., Shah, P. K., and Fuster, V. (1995). Coronary plaque disruption. Circulation. 92, 657-671. doi: 10.1161/01.CIR.92.3.657

Fang, H., Wang, P. F., Zhou, Y., Wang, Y. C., and Yang, Q. W. (2013). Toll-like receptor 4 signaling in intracerebral hemorrhage-induced inflammation and injury. J. Neuroinflammation 10, 27. doi: 10.1186/1742-2094-10-27

Fenton, H. J. H. (1894). LXXIII.-Oxidation of tartaric acid in presence of iron. J. Chem. Soc. Trans. 65, 899-910. doi:10.1039/ct8946500899

Fernandez, P. L., Dutra, F. F., Alves, L., Figueiredo, R. T., Mourao-Sa, D., Fortes, G. B., et al. (2010). Heme amplifies the innate immune response to microbial molecules through spleen tyrosine kinase (Syk)-dependent reactive oxygen species generation. J. Biol. Chem. 285, 32844-32851. doi: 10.1074/jbc.M110. 146076

Ferreira, A., Marguti, I., Bechmann, I., Jeney, V., Chora, A., Palha, N. R., et al. (2011). Sickle hemoglobin confers tolerance to Plasmodium infection. Cell 145, 398-409. doi: 10.1016/j.cell.2011.03.049

Ferris, C. D., Jaffrey, S. R., Sawa, A., Takahashi, M., Brady, S. D., Barrow, R. K., et al. (1999). Haem oxygenase-1 prevents cell death by regulating cellular iron. Nat. Cell Biol. 1, 152-157.

Figueiredo, R. T., Fernandez, P. L., Mourao-Sa, D. S., Porto, B. N., Dutra, F. F., Alves, L. S., et al. (2007). Characterization of heme as activator of Toll-like receptor 4. J. Biol. Chem. 282, 20221-20229. doi: 10.1074/jbc.M610737200

Fortes, G. B., Alves, L. S., de Oliveira, R., Dutra, F. F., Rodrigues, D., Fernandez, P. L., et al. (2012). Heme induces programmed necrosis on macrophages through autocrine TNF and ROS production. Blood 119, 2368-2375. doi: 10.1182/blood2011-08-375303

Francis, S. E., Sullivan, D. J. Jr., and Goldberg, D. E. (1997). Hemoglobin metabolism in the malaria parasite Plasmodium falciparum. Annu. Rev. Microbiol. 51, 97-123. doi: 10.1146/annurev.micro.51.1.97

Frimat, M., Tabarin, F., Dimitrov, J. D., Poitou, C., Halbwachs-Mecarelli, L., Fremeaux-Bacchi, V., et al. (2013). Complement activation by heme as a secondary hit for atypical hemolytic uremic syndrome. Blood 122, 282-292. doi: 10.1182/blood-2013-03-489245 
Fuchs, T. A., Brill, A., Duerschmied, D., Schatzberg, D., Monestier, M., Myers, D. D. Jr., et al. (2010). Extracellular DNA traps promote thrombosis. Proc. Natl. Acad. Sci. U.S.A. 107, 15880-15885. doi: 10.1073/pnas. 1005743107

Gantner, B. N., Simmons, R. M., Canavera, S. J., Akira, S., and Underhill, D. M. (2003). Collaborative induction of inflammatory responses by dectin1 and Toll-like receptor 2. J. Exp. Med. 197, 1107-1117. doi: 10.1084/jem. 20021787

Gao, B., and Tsan, M. F. (2003). Endotoxin contamination in recombinant human heat shock protein 70 (Hsp70) preparation is responsible for the induction of tumor necrosis factor alpha release by murine macrophages. J. Biol. Chem. 278, 174-179. doi: 10.1074/jbc.M208742200

Georgel, P., Jiang, Z., Kunz, S., Janssen, E., Mols, J., Hoebe, K., et al. (2007). Vesicular stomatitis virus glycoprotein $\mathrm{G}$ activates a specific antiviral Toll-like receptor 4-dependent pathway. Virology 362, 304-313. doi: 10.1016/j.virol.2006.12.032

Ghosh, S., Adisa, O. A., Chappa, P., Tan, F., Jackson, K. A., Archer, D. R., et al. (2013). Extracellular hemin crisis triggers acute chest syndrome in sickle mice. J. Clin. Invest. 123, 4809-4820. doi: 10.1172/JCI64578

Gladwin, M. T., and Vichinsky, E. (2008). Pulmonary complications of sickle cell disease. N. Engl. J. Med. 359, 2254-2265. doi: 10.1056/NEJMra0804411

Gozzelino, R., Andrade, B. B., Larsen, R., Luz, N. F., Vanoaica, L., Seixas, E., et al. (2012). Metabolic adaptation to tissue iron overload confers tolerance to malaria. Cell Host Microbe 12, 693-704. doi: 10.1016/j.chom.2012.10.011

Gozzelino, R., Jeney, V., and Soares, M. P. (2010). Mechanisms of cell protection by heme oxygenase-1. Annu. Rev. Pharmacol. Toxicol. 50, 323-354. doi: 10.1146/annurev.pharmtox.010909.105600

Gozzelino, R., and Soares, M. P. (2011). Heme sensitization to TNF-mediated programmed cell death. Adv. Exp. Med. Biol. 691, 211-219. doi: 10.1007/9781-4419-6612-4_22

Graça-Souza, A. V., Arruda, M. A., de Freitas, M. S., Barja-Fidalgo, C., and Oliveira, P. L. (2002). Neutrophil activation by heme: implications for inflammatory processes. Blood 99, 4160-4165. doi: 10.1182/blood.V99.11.4160

Gu, Y., Hua, Y., Keep, R. F., Morgenstern, L. B., and Xi, G. (2009). Deferoxamine reduces intracerebral hematoma-induced iron accumulation and neuronal death in piglets. Stroke 40, 2241-2243. doi: 10.1161/STROKEAHA.108.539536

Guyton, J. R., and Klemp, K. F. (1996). Development of the lipid-rich core in human atherosclerosis. Arterioscler. Thromb. Vasc. Biol. 16, 4-11. doi 10.1161/01.ATV.16.1.4

Hahalis, G., Kremastinos, D. T., Terzis, G., Kalogeropoulos, A. P., Chrysanthopoulou, A., Karakantza, M., et al. (2008). Global vasomotor dysfunction and accelerated vascular aging in beta-thalassemia major. Atherosclerosis 198, 448-457. doi: 10.1016/j.atherosclerosis.2007.09.030

Halle, A., Hornung, V., Petzold, G. C., Stewart, C. R., Monks, B. G., Reinheckel, T., et al. (2008). The NALP3 inflammasome is involved in the innate immune response to amyloid-beta. Nat. Immunol. 9, 857-865. doi: 10.1038/ ni. 1636

Harel, S., and Kanner, J. (1988). The generation of ferryl or hydroxyl radicals during interaction of haemproteins with hydrogen peroxide. Free Radic. Res. Commun. 5, 21-33. doi: 10.3109/10715768809068555

He, S., Wang, L., Miao, L., Wang, T., Du, F., Zhao, L., et al. (2009). Receptor interacting protein kinase-3 determines cellular necrotic response to TNF-alpha. Cell 137, 1100-1111. doi: 10.1016/j.cell.2009.05.021

Hebbel, R. P. (1991). Beyond hemoglobin polymerization: the red blood cell membrane and sickle disease pathophysiology. Blood 77, 214-237.

Heinle, R. W., and Read, M. R. (1948). Study of thalassemia minor in three generations of an Italian family. Blood 3, 449-456.

Hoebe, K., Du, X., Georgel, P., Janssen, E., Tabeta, K., Kim, S. O., et al. (2003). Identification of Lps2 as a key transducer of MyD88-independent TIR signalling. Nature 424, 743-748. doi: 10.1038/nature01889

Hornung, V., Bauernfeind, F., Halle, A., Samstad, E. O., Kono, H., Rock, K. L., et al. (2008). Silica crystals and aluminum salts activate the NALP3 inflammasome through phagosomal destabilization. Nat. Immunol. 9, 847-856. doi: 10.1038/ni.1631

Hovav, T., Goldfarb, A., Artmann, G., Yedgar, S., and Barshtein, G. (1999). Enhanced adherence of beta-thalassaemic erythrocytes to endothelial cells. Br. J. Haematol. 106, 178-181. doi: 10.1046/j.1365-2141.1999.01489.x

Hvidberg, V., Maniecki, M. B., Jacobsen, C., Hojrup, P., Moller, H. J., and Moestrup, S. K. (2005). Identification of the receptor scavenging hemopexin-heme complexes. Blood 106, 2572-2579. doi: 10.1182/blood-2005-03-1185
Ingram, V. M. (1957). Gene mutations in human haemoglobin: the chemical difference between normal and sickle cell haemoglobin. Nature 180, 326-328. doi: $10.1038 / 180326 \mathrm{a} 0$

Iyer, S. S., He, Q., Janczy, J. R., Elliott, E. I., Zhong, Z., Olivier, A. K., et al. (2013). Mitochondrial cardiolipin is required for Nlrp3 inflammasome activation. Immunity 39, 311-323. doi: 10.1016/j.immuni.2013.08.001

Iyer, S. S., Pulskens, W. P., Sadler, J. J., Butter, L. M., Teske, G. J., Ulland, T. K., et al. (2009). Necrotic cells trigger a sterile inflammatory response through the Nlrp3 inflammasome. Proc. Natl. Acad. Sci. U.S.A. 106, 20388-20393. doi: 10.1073/pnas.0908698106

Janeway, C. A. Jr. (1989). Approaching the asymptote? Evolution and revolution in immunology. Cold. Spring Harb. Symp. Quant. Biol. 54(Pt 1), 1-13. doi: 10.1101/SQB.1989.054.01.003

Jeney, V., Balla, J., Yachie, A., Varga, Z., Vercellotti, G. M., Eaton, J. W., et al. (2002). Pro-oxidant and cytotoxic effects of circulating heme. Blood 100, 879-887. doi: 10.1182/blood.V100.3.879

Juckett, M. B., Balla, J., Balla, G., Jessurun, J., Jacob, H. S., and Vercellotti, G. M. (1995). Ferritin protects endothelial cells from oxidized low density lipoprotein in vitro. Am. J. Pathol. 147, 782-789.

Kamata, H., Honda, S., Maeda, S., Chang, L., Hirata, H., and Karin, M. (2005). Reactive oxygen species promote TNFalpha-induced death and sustained JNK activation by inhibiting MAP kinase phosphatases. Cell 120, 649-661. doi: 10.1016/j.cell.2004.12.041

Katori, M., Buelow, R., Ke, B., Ma, J., Coito, A. J., Iyer, S., et al. (2002). Heme oxygenase-1 overexpression protects rat hearts from cold ischemia/reperfusion injury via an antiapoptotic pathway. Transplantation 73, 287-292. doi: 10.1097/00007890-200201270-00023

Kaul, D. K., and Hebbel, R. P. (2000). Hypoxia/reoxygenation causes inflammatory response in transgenic sickle mice but not in normal mice. J. Clin. Invest. 106, 411-420. doi: 10.1172/JCI9225

Keel, S. B., Doty, R. T., Yang, Z., Quigley, J. G., Chen, J., Knoblaugh, S., et al. (2008). A heme export protein is required for red blood cell differentiation and iron homeostasis. Science 319, 825-828. doi: 10.1126/science.1151133

Khandros, E., Thom, C. S., D’Souza, J., and Weiss, M. J. (2012). Integrated protein quality-control pathways regulate free alpha-globin in murine beta-thalassemia. Blood 119, 5265-5275. doi: 10.1182/blood-2011-12-397729

Kim, S. J., and Lee, S. M. (2013). NLRP3 inflammasome activation in D-galactosamine and lipopolysaccharide-induced acute liver failure: role of heme oxygenase-1. Free Radic. Biol. Med. 65, 997-1004. doi: 10.1016/j.freeradbiomed.2013.08.178

Kolodgie, F. D., Gold, H. K., Burke, A. P., Fowler, D. R., Kruth, H. S., Weber, D. K., et al. (2003). Intraplaque hemorrhage and progression of coronary atheroma. N. Engl. J. Med. 349, 2316-2325. doi: 10.1056/NEJMoa035655

Kovtunovych, G., Eckhaus, M. A., Ghosh, M. C., Ollivierre-Wilson, H., and Rouault, T. A. (2010). Dysfunction of the heme recycling system in heme oxygenase 1deficient mice: effects on macrophage viability and tissue iron distribution. Blood 116, 6054-6062. doi: 10.1182/blood-2010-03-272138

Krishnamurthy, P., Ross, D. D., Nakanishi, T., Bailey-Dell, K., Zhou, S., Mercer, K. E., et al. (2004). The stem cell marker Bcrp/ABCG2 enhances hypoxic cell survival through interactions with heme. J. Biol. Chem. 279, 24218-24225. doi: 10.1074/jbc.M313599200

Krishnamurthy, P., and Schuetz, J. D. (2006). Role of ABCG2/BCRP in biology and medicine. Annu. Rev. Pharmacol. Toxicol. 46, 381-410. doi: 10.1146/annurev.pharmtox.46.120604.141238

Krishnamurthy, P. C., Du, G., Fukuda, Y., Sun, D., Sampath, J., Mercer, K. E., et al. (2006). Identification of a mammalian mitochondrial porphyrin transporter. Nature 443, 586-589. doi: 10.1038/nature05125

Kristiansen, M., Graversen, J. H., Jacobsen, C., Sonne, O., Hoffman, H. J., Law, S. K., et al. (2001). Identification of the haemoglobin scavenger receptor. Nature 409, 198-201. doi: 10.1038/35051594

Kumar, S., and Bandyopadhyay, U. (2005). Free heme toxicity and its detoxification systems in human. Toxicol Lett. 157, 175-188. doi: 10.1016/j.toxlet.2005.03.004

Kwon, H. M., Sangiorgi, G., Ritman, E. L., McKenna, C., Holmes, D. R. Jr., Schwartz, R. S., et al. (1998). Enhanced coronary vasa vasorum neovascularization in experimental hypercholesterolemia. J. Clin. Invest. 101, 1551-1556. doi: 10.1172/JCI1568

Lad, L., Schuller, D. J., Shimizu, H., Friedman, J., Li, H., Ortiz de Montellano, P. R., etal. (2003). Comparison of the heme-free and -bound crystal 
structures of human heme oxygenase-1. J. Biol. Chem. 278, 7834-7843. doi: 10.1074/jbc.M211450200

Laird, M. D., Wakade, C., Alleyne, C. H. Jr., and Dhandapani, K. M. (2008). Hemin-induced necroptosis involves glutathione depletion in mouse astrocytes. Free Radic. Biol. Med. 45, 1103-1114. doi: 10.1016/j.freeradbiomed.2008. 07.003

Larsen, R., Gouveia, Z., Soares, M. P., and Gozzelino, R. (2012). Heme cytotoxicity and the pathogenesis of immune-mediated inflammatory diseases. Front Pharmacol. 3:77. doi: 10.3389/fphar.2012.00077

Larsen, R., Gozzelino, R., Jeney, V., Tokaji, L., Bozza, F. A., Japiassu, A. M., etal. (2010). A central role for free heme in the pathogenesis of severe sepsis. Sci. Transl. Med. 2, 51ra71. doi: 10.1126/scitranslmed. 3001118

Latunde-Dada, G. O., Takeuchi, K., Simpson, R. J., and McKie, A. T. (2006). Haem carrier protein 1 ( $\mathrm{HCP} 1)$ : expression and functional studies in cultured cells. FEBS Lett. 580, 6865-6870. doi: 10.1016/j.febslet.2006.11.048

Latz, E., Xiao, T. S., and Stutz, A. (2013). Activation and regulation of the inflammasomes. Nat. Rev. Immunol. 13, 397-411. doi: 10.1038/nri3452

Lee, J. Y., Keep, R. F., He, Y., Sagher, O., Hua, Y., and Xi, G. (2010). Hemoglobin and iron handling in brain after subarachnoid hemorrhage and the effect of deferoxamine on early brain injury. J. Cereb. Blood Flow Metab. 30, 1793-1803. doi: $10.1038 /$ jcbfm.2010.137

Levi, S., Yewdall, S. J., Harrison, P. M., Santambrogio, P., Cozzi, A., Rovida, E., et al. (1992). Evidence of $\mathrm{H}$ - and L-chains have co-operative roles in the iron-uptake mechanism of human ferritin. Biochem. J. 288(Pt 2), 591-596.

Li, Q., Fu, W., Yao, J., Ji, Z., Wang, Y., Zhou, Z., et al. (2014). Heme induces IL$1 \beta$ secretion through activating NLRP3 in kidney inflammation. Cell Biochem. Biophys. doi: 10.1007/s12013-014-9823-9 [Epub ahead of print].

Libby, P., Ridker, P. M., and Maseri, A. (2002). Inflammation and atherosclerosis. Circulation 105, 1135-1143. doi: 10.1161/hc0902.104353

Light, W. R. III, and Olson, J. S. (1990a). The effects of lipid composition on the rate and extent of heme binding to membranes. J. Biol. Chem. 265, 15632-15637.

Light, W. R. III, and Olson, J. S. (1990b). Transmembrane movement of heme. J. Biol. Chem. 265, 15623-15631.

Lin, S., Yin, Q., Zhong, Q., Lv, F. L., Zhou, Y., Li, J. Q., etal. (2012). Heme activates TLR4-mediated inflammatory injury via MyD88/TRIF signaling pathway in intracerebral hemorrhage. J Neuroinflammation 9, 46. doi: 10.1186/1742-2094-9-46

Lin, T., Kwak, Y. H., Sammy, F., He, P., Thundivalappil, S., Sun, G., et al. (2010). Synergistic inflammation is induced by blood degradation products with microbial Toll-like receptor agonists and is blocked by hemopexin. J. Infect. Dis. 202, 624-632. doi: 10.1086/654929

Liu, M., Wilson, N. O., Hibbert, J. M., and Stiles, J. K. (2013). STAT3 regulates MMP3 in heme-induced endothelial cell apoptosis. PLOS ONE 8:e71366. doi: 10.1371/journal.pone.0071366

Loirat, C., and Fremeaux-Bacchi, V. (2011). Atypical hemolytic uremic syndrome. Orphanet J. Rare Dis. 6, 60. doi: 10.1186/1750-1172-6-60

Lu, N., Yi, L., Deng, Q., Li, J., Gao, Z., and Li, H. (2012). The interaction between desferrioxamine and hemin: a potential toxicological implication. Toxicol. In Vitro 26, 732-735. doi: 10.1016/j.tiv.2012.03.006

Luo, Y. P., Jiang, L., Kang, K., Fei, D. S., Meng, X. L., Nan, C. C., et al. (2014). Hemin inhibits NLRP3 inflammasome activation in sepsis-induced acute lung injury, involving heme oxygenase-1. Int. Immunopharmacol. 20, 24-32. doi: 10.1016/j.intimp.2014.02.017

Lyoumi, S., Puy, H., Tamion, F., Bogard, C., Leplingard, A., Scotte, M., et al. (1999). Heme and acute inflammation role in vivo of heme in the hepatic expression of positive acute-phase reactants in rats. Eur. J. Biochem. 261, 190-196. doi: 10.1046/j.1432-1327.1999.00254.x

Ma, Q., Chen, S., Hu, Q., Feng, H., Zhang, J. H., and Tang, J. (2014). NLRP3 inflammasome contributes to inflammation after intracerebral hemorrhage. Ann. Neurol. 75, 209-219. doi: 10.1002/ana.24070

Mao, G. D., Thomas, P. D., and Poznansky, M. J. (1994). Oxidation of spin trap 5,5-dimethyl-1-pyrroline-1-oxide in an electron paramagnetic resonance study of the reaction of methemoglobin with hydrogen peroxide. Free Radic. Biol. Med. 16, 493-500. doi: 10.1016/0891-5849(94)90127-9

Mariathasan, S., Weiss, D. S., Newton, K., McBride, J., O’Rourke, K., Roose-Girma, M., et al. (2006). Cryopyrin activates the inflammasome in response to toxins and ATP. Nature 440, 228-232. doi: 10.1038/nature04515
Martinon, F., Burns, K., and Tschopp, J. (2002). The inflammasome: a molecular platform triggering activation of inflammatory caspases and processing of proILbeta. Mol. Cell 10, 417-426. doi: 10.1016/S1097-2765(02)00599-3

Martinon, F., Petrilli, V., Mayor, A., Tardivel, A., and Tschopp, J. (2006). Goutassociated uric acid crystals activate the NALP3 inflammasome. Nature 440, 237241. doi: 10.1038/nature04516

Massberg, S., Grahl, L., von Bruehl, M. L., Manukyan, D., Pfeiler, S., Goosmann, C., et al. (2010). Reciprocal coupling of coagulation and innate immunity via neutrophil serine proteases. Nat. Med. 16, 887-896. doi: 10.1038/nm.2184

Mata-Haro, V., Cekic, C., Martin, M., Chilton, P. M., Casella, C. R., and Mitchell, T. C. (2007). The vaccine adjuvant monophosphoryl lipid A as a TRIF-biased agonist of TLR4. Science 316, 1628-1632. doi: 10.1126/science.1138963

Matsui, N. M., Borsig, L., Rosen, S. D., Yaghmai, M., Varki, A., and Embury, S. H. (2001). P-selectin mediates the adhesion of sickle erythrocytes to the endothelium. Blood 98, 1955-1962.

Medzhitov, R. (2008). Origin and physiological roles of inflammation. Nature 454, 428-435. doi: 10.1038/nature07201

Medzhitov, R., Preston-Hurlburt, P., and Janeway, C. A. Jr. (1997). A human homologue of the Drosophila Toll protein signals activation of adaptive immunity. Nature 388, 394-397. doi: 10.1038/41131

Melamed-Frank, M., Lache, O., Enav, B. I., Szafranek, T., Levy, N. S., Ricklis, R. M., et al. (2001). Structure-function analysis of the antioxidant properties of haptoglobin. Blood 98, 3693-3698. doi: 10.1182/blood.V98.13.3693

Michel, J. B., Virmani, R., Arbustini, E., and Pasterkamp, G. (2011). Intraplaque haemorrhages as the trigger of plaque vulnerability. Eur. Heart J. 32, 1977-1985, 1985a, 1985b, 1985c.

Mócsai, A. (2013). Diverse novel functions of neutrophils in immunity, inflammation, and beyond. J. Exp. Med. 210, 1283-1299. doi: 10.1084/jem.20122220

Mold, C., Tamerius, J. D., and Phillips, G. Jr. (1995). Complement activation during painful crisis in sickle cell anemia. Clin. Immunol. Immunopathol. 76, 314-320. doi: 10.1006/clin.1995.1131

Monteiro, A. P., Pinheiro, C. S., Luna-Gomes, T., Alves, L. R., Maya-Monteiro, C. M., Porto, B. N., et al. (2011). Leukotriene B4 mediates neutrophil migration induced by heme. J. Immunol. 186, 6562-6567. doi: 10.4049/jimmunol.1002400

Moore, K. J., Sheedy, F. J., and Fisher, E. A. (2013). Macrophages in atherosclerosis: a dynamic balance. Nat. Rev. Immunol. 13, 709-721. doi: 10.1038/nri3520

Moore, K. J., and Tabas, I. (2011). Macrophages in the pathogenesis of atherosclerosis. Cell 145, 341-355. doi: 10.1016/j.cell.2011.04.005

Moraes, J. A., Barcellos-de-Souza, P., Rodrigues, G., Nascimento-Silva, V., Silva, S. V., Assreuy, J., et al. (2012). Heme modulates smooth muscle cell proliferation and migration via NADPH oxidase: a counter-regulatory role for heme oxygenase system. Atherosclerosis 224, 394-400. doi: 10.1016/j.atherosclerosis.2012.07.043

Muller-Eberhard, U. (1970). Hemopexin. N. Engl. J. Med. 283, 1090-1094. doi: 10.1056/NEJM197011122832007

Muller-Eberhard, U., Javid, J., Liem, H. H., Hanstein, A., and Hanna, M. (1968). Plasma concentrations of hemopexin, haptoglobin and heme in patients with various hemolytic diseases. Blood 32, 811-815.

Muñoz-Planillo, R., Kuffa, P., Martinez-Colon, G., Smith, B. L., Rajendiran, T. M., and Nunez, G. (2013). K(+) efflux is the common trigger of NLRP3 inflammasome activation by bacterial toxins and particulate matter. Immunity 38 , 1142-1153. doi: 10.1016/j.immuni.2013.05.016

Muzio, M., Ni, J., Feng, P., and Dixit, V. M. (1997). IRAK (Pelle) family member IRAK-2 and MyD88 as proximal mediators of IL-1 signaling. Science 278, 16121615. doi: 10.1126/science.278.5343.1612

Nagy, E., Eaton, J. W., Jeney, V., Soares, M. P., Varga, Z., Galajda, Z., et al. (2010). Red cells, hemoglobin, heme, iron, and atherogenesis. Arterioscler. Thromb. Vasc. Biol. 30, 1347-1353. doi: 10.1161/ATVBAHA.110.206433

Nan, Y., Wang, R., Zhao, S., Han, F., Wu, W. J., Kong, L., et al. (2010). Heme oxygenase-1 prevents non-alcoholic steatohepatitis through suppressing hepatocyte apoptosis in mice. Lipids Health Dis. 9, 124. doi: 10.1186/1476-511X9-124

Natarajan, R., Fisher, B. J., and Fowler, A. A. III. (2007). Hypoxia inducible factor-1 modulates hemin-induced IL- 8 secretion in microvascular endothelium. Microvasc. Res. 73, 163-172. doi: 10.1016/j.mvr.2007.01.002

Nath, K. A., Haggard, J. J., Croatt, A. J., Grande, J. P., Poss, K. D., and Alam, J. (2000). The indispensability of heme oxygenase-1 in protecting against acute heme protein-induced toxicity in vivo. Am. J. Pathol. 156, 1527-1535. doi: 10.1016/S0002-9440(10)65024-9 
Nathan, C., and Ding, A. (2010). Nonresolving inflammation. Cell 140, 871-882. doi: 10.1016/j.cell.2010.02.029

Ng, G., Sharma, K., Ward, S. M., Desrosiers, M. D., Stephens, L. A., Schoel, W. M., et al. (2008). Receptor-independent, direct membrane binding leads to cellsurface lipid sorting and Syk kinase activation in dendritic cells. Immunity 29, 807-818. doi: 10.1016/j.immuni.2008.09.013

Noris, M., and Remuzzi, G. (2009). Atypical hemolytic-uremic syndrome. N. Engl. J. Med. 361, 1676-1687. doi: 10.1056/NEJMra0902814

Oliveira, J. H., Goncalves, R. L., Lara, F. A., Dias, F. A., Gandara, A. C., MennaBarreto, R. F., et al. (2011). Blood meal-derived heme decreases ROS levels in the midgut of Aedes aegypti and allows proliferation of intestinal microbiota. PLoS Pathog. 7:e1001320. doi: 10.1371/journal.ppat.1001320

Oliveira, M. F., Silva, J. R., Dansa-Petretski, M., de Souza, W., Lins, U., Braga, C. M., et al. (1999). Haem detoxification by an insect. Nature 400, 517-518. doi: $10.1038 / 22910$

Oliveira, P. L., Kawooya, J. K., Ribeiro, J. M., Meyer, T., Poorman, R., Alves, E. W., et al. (1995). A heme-binding protein from hemolymph and oocytes of the blood-sucking insect, Rhodnius prolixus. Isolation and characterization. J. Biol. Chem. 270, 10897-10901. doi: 10.1074/jbc.270.18.10897

Olivier, M., Van Den Ham, K., Shio, M. T., Kassa, F. A., and Fougeray, S. (2014). Malarial pigment hemozoin and the innate inflammatory response. Front. Immunol. 5:25. doi: 10.3389/fimmu.2014.00025

Oka, T., Hikoso, S., Yamaguchi, O., Taneike, M., Takeda, T., Tamai, T., et al. (2012). Mitochondrial DNA that escapes from autophagy causes inflammation and heart failure. Nature 485, 251-255. doi: 10.1038/nature10992

Otterbein, L. E., Bach, F. H., Alam, J., Soares, M., Tao Lu, H., Wysk, M., et al. (2000) Carbon monoxide has anti-inflammatory effects involving the mitogen-activated protein kinase pathway. Nat. Med. 6, 422-428. doi: 10.1038/74680

Paes, M. C., Oliveira, M. B., and Oliveira, P. L. (2001). Hydrogen peroxide detoxification in the midgut of the blood-sucking insect, Rhodnius prolixus. Arch. Insect Biochem. Physiol. 48, 63-71. doi: 10.1002/arch.1058

Paiva-Silva, G. O., Cruz-Oliveira, C., Nakayasu, E. S., Maya-Monteiro, C. M., Dunkov, B. C., Masuda, H., etal. (2006). A heme-degradation pathway in a blood-sucking insect. Proc. Natl. Acad. Sci. U.S.A. 103, 8030-8035. doi: 10.1073/pnas.0602224103

Pamplona, A., Ferreira, A., Balla, J., Jeney, V., Balla, G., Epiphanio, S., et al. (2007). Heme oxygenase-1 and carbon monoxide suppress the pathogenesis of experimental cerebral malaria. Nat. Med. 13, 703-710. doi: 10.1038/nm1586

Pandey, A. V., and Tekwani, B. L. (1996). Formation of haemozoin/beta-haematin under physiological conditions is not spontaneous. FEBS Lett. 393, 189-193. doi: 10.1016/0014-5793(96)00881-2

Paoli, M., Anderson, B. F., Baker, H. M., Morgan, W. T., Smith, A., and Baker, E. N. (1999). Crystal structure of hemopexin reveals a novel high-affinity heme site formed between two beta-propeller domains. Nat. Struct. Biol. 6, 926-931. doi: $10.1038 / 13294$

Park, B. S., Song, D. H., Kim, H. M., Choi, B. S., Lee, H., and Lee, J. O. (2009). The structural basis of lipopolysaccharide recognition by the TLR4-MD-2 complex. Nature 458, 1191-1195. doi: 10.1038/nature07830

Park, S. Y., Yokoyama, T., Shibayama, N., Shiro, Y., and Tame, J. R. (2006) 1.25 A resolution crystal structures of human haemoglobin in the oxy, deoxy and carbonmonoxy forms. J. Mol. Biol. 360, 690-701. doi: 10.1016/j.jmb.2006.05.036

Parroche, P., Lauw, F. N., Goutagny, N., Latz, E., Monks, B. G., Visintin, A., et al. (2007). Malaria hemozoin is immunologically inert but radically enhances innate responses by presenting malaria DNA to Toll-like receptor 9. Proc. Natl. Acad. Sci. U.S.A. 104, 1919-1924. doi: 10.1073/pnas.0608745104

Pászty, C., Brion, C. M., Manci, E., Witkowska, H. E., Stevens, M. E., Mohandas, N., et al. (1997). Transgenic knockout mice with exclusively human sickle hemoglobin and sickle cell disease. Science 278, 876-878. doi: 10.1126/science.278.5339.876

Patel, R. P., Svistunenko, D. A., Darley-Usmar, V. M., Symons, M. C., and Wilson, M. T. (1996). Redox cycling of human methaemoglobin by $\mathrm{H}_{2} \mathrm{O}_{2}$ yields persistent ferryl iron and protein based radicals. Free Radic. Res. 25, 117-123. doi: $10.3109 / 10715769609149916$

Pauling, L., Itano, H. A., Singer, S. J., and Wells, I. C. (1949). Sickle cell anemia, a molecular disease. Science 109, 543-548. doi: 10.1126/science.110.2865.543

Pawluczkowycz, A. W., Lindorfer, M. A., Waitumbi, J. N., and Taylor, R. P. (2007). Hematin promotes complement alternative pathway-mediated deposition of C3 activation fragments on human erythrocytes: potential implications for the pathogenesis of anemia in malaria. J. Immunol. 179, 5543-5552. doi: 10.4049/jimmunol.179.8.5543

Pereira, L. O., Oliveira, P. L., Almeida, I. C., and Paiva-Silva, G. O. (2007). Biglutaminyl-biliverdin IX alpha as a heme degradation product in the dengue fever insect-vector Aedes aegypti. Biochemistry 46, 6822-6829. doi: 10.1021/bi700011d

Petrilli, V., Papin, S., Dostert, C., Mayor, A., Martinon, F., and Tschopp, J. (2007). Activation of the NALP3 inflammasome is triggered by low intracellular potassium concentration. Cell Death Differ. 14, 1583-1589. doi: 10.1038/sj.cdd.4402195

Pham, C. G., Bubici, C., Zazzeroni, F., Papa, S., Jones, J., Alvarez, K., et al. (2004). Ferritin heavy chain upregulation by NF-kappaB inhibits TNFalphainduced apoptosis by suppressing reactive oxygen species. Cell 119, 529-542. doi: 10.1016/j.cell.2004.10.017

Philippidis, P., Mason, J. C., Evans, B. J., Nadra, I., Taylor, K. M., Haskard, D. O., et al. (2004). Hemoglobin scavenger receptor CD163 mediates interleukin-10 release and heme oxygenase-1 synthesis: antiinflammatory monocyte-macrophage responses in vitro, in resolving skin blisters in vivo, and after cardiopulmonary bypass surgery. Circ. Res. 94, 119-126. doi: 10.1161/01.RES.0000109414.78907.F9

Piazza, M., Damore, G., Costa, B., Gioannini, T. L., Weiss, J. P., and Peri, F. (2011). Hemin and a metabolic derivative coprohemin modulate the TLR4 pathway differently through different molecular targets. Innate Immun. 17, 293-301. doi: $10.1177 / 1753425910369020$

Porto, B. N., Alves, L. S., Fernandez, P. L., Dutra, T. P., Figueiredo, R. T., Graca-Souza, A. V., et al. (2007). Heme induces neutrophil migration and reactive oxygen species generation through signaling pathways characteristic of chemotactic receptors. J. Biol. Chem. 282, 24430-24436. doi: 10.1074/jbc.M703570200

Poss, K. D., and Tonegawa, S. (1997a). Heme oxygenase 1 is required for mammalian iron reutilization. Proc. Natl. Acad. Sci. U.S.A. 94, 10919-10924. doi: 10.1073/pnas.94.20.10919

Poss, K. D., and Tonegawa, S. (1997b). Reduced stress defense in heme oxygenase 1-deficient cells. Proc. Natl. Acad. Sci. U.S.A. 94, 10925-10930. doi: 10.1073/pnas.94.20.10925

Potor, L., Banyai, E., Becs, G., Soares, M. P., Balla, G., Balla, J., et al. (2013). Atherogenesis may involve the prooxidant and proinflammatory effects of ferryl hemoglobin. Oxid. Med. Cell. Longev. 2013, 676425. doi: 10.1155/2013/676425

Qiu, A., Jansen, M., Sakaris, A., Min, S. H., Chattopadhyay, S., Tsai, E., et al. (2006). Identification of an intestinal folate transporter and the molecular basis for hereditary folate malabsorption. Cell 127, 917-928. doi: 10.1016/j.cell.2006.09.041

Quaye, I. K. (2008). Haptoglobin, inflammation and disease. Trans. R. Soc. Trop. Med. Hyg. 102, 735-742. doi: 10.1016/j.trstmh.2008.04.010

Quigley, J. G., Yang, Z., Worthington, M. T., Phillips, J. D., Sabo, K. M., Sabath, D. E., et al. (2004). Identification of a human heme exporter that is essential for erythropoiesis. Cell 118, 757-766. doi: 10.1016/j.cell.2004.08.014

Rajagopal, A., Rao, A. U., Amigo, J., Tian, M., Upadhyay, S. K., Hall, C., et al. (2008). Haem homeostasis is regulated by the conserved and concerted functions of HRG-1 proteins. Nature 453, 1127-1131. doi: 10.1038/nature06934

Regan, R. F., Wang, Y., Ma, X., Chong, A., and Guo, Y. (2001). Activation of extracellular signal-regulated kinases potentiates hemin toxicity in astrocyte cultures. J. Neurochem. 79, 545-555. doi: 10.1046/j.1471-4159.2001.00590.x

Reiter, C. D., Wang, X., Tanus-Santos, J. E., Hogg, N., Cannon, R. O. III, Schechter, A. N., et al. (2002). Cell-free hemoglobin limits nitric oxide bioavailability in sickle-cell disease. Nat. Med. 8, 1383-1389. doi: 10.1038/nm1202-799

Rose, M. Y., Thompson, R. A., Light, W. R., and Olson, J. S. (1985). Heme transfer between phospholipid membranes and uptake by apohemoglobin. J. Biol. Chem. 260, 6632-6640.

Rot, A., and von Andrian, U. H. (2004). Chemokines in innate and adaptive host defense: basic chemokinese grammar for immune cells. Annu. Rev. Immunol. 22, 891-928. doi: 10.1146/annurev.immunol.22.012703.104543

Ruiz-Torres, M. P., Casiraghi, F., Galbusera, M., Macconi, D., Gastoldi, S., Todeschini, M., et al. (2005). Complement activation: the missing link between ADAMTS-13 deficiency and microvascular thrombosis of thrombotic microangiopathies. Thromb. Haemost. 93, 443-452. doi: 10.1267/THRO05030443

Ryan, T. M., Ciavatta, D. J., and Townes, T. M. (1997). Knockout-transgenic mouse model of sickle cell disease. Science 278, 873-876. doi: 10.1126/science.278.5339.873

Ryter, S. W., and Tyrrell, R. M. (2000). The heme synthesis and degradation pathways: role in oxidant sensitivity. Heme oxygenase has both pro- and 
antioxidant properties. Free Radic. Biol. Med. 28, 289-309. doi: 10.1016/S08915849(99)00223-3

Sansing, L. H., Harris, T. H., Welsh, F. A., Kasner, S. E., Hunter, C. A., and Kariko, K. (2011). Toll-like receptor 4 contributes to poor outcome after intracerebral hemorrhage. Ann. Neurol. 70, 646-656. doi: 10.1002/ana.22528

Schmidt, M., Raghavan, B., Muller, V., Vogl, T., Fejer, G., Tchaptchet, S., et al. (2010). Crucial role for human Toll-like receptor 4 in the development of contact allergy to nickel. Nat. Immunol. 11, 814-819. doi: 10.1038/ni.1919

Schmitt, T. H., Frezzatti, W. A. Jr., and Schreier, S. (1993). Hemin-induced lipid membrane disorder and increased permeability: a molecular model for the mechanism of cell lysis. Arch. Biochem. Biophys. 307, 96-103. doi: 10.1006/abbi.1993.1566

Schimmel, M., Nur, E., Biemond, B. J., van Mierlo, G. J., Solati, S., Brandjes, D. P., et al. (2013). Nucleosomes and neutrophil activation in sickle cell disease painful crisis. Haematologica 98, 1797-1803. doi: 10.3324/haematol.2013.088021

Seixas, E., Gozzelino, R., Chora, A., Ferreira, A., Silva, G., Larsen, R., et al. (2009). Heme oxygenase- 1 affords protection against noncerebral forms of severe malaria. Proc. Natl. Acad. Sci. U.S.A. 106, 15837-15842. doi: 10.1073/pnas.0903419106

Shayeghi, M., Latunde-Dada, G. O., Oakhill, J. S., Laftah, A. H., Takeuchi, K., Halliday, N., et al. (2005). Identification of an intestinal heme transporter. Cell 122, 789-801. doi: 10.1016/j.cell.2005.06.025

Shimada, K., Crother, T. R., Karlin, J., Dagvadorj, J., Chiba, N., Chen, S., et al. (2012). Oxidized mitochondrial DNA activates the NLRP3 inflammasome during apoptosis. Immunity 36, 401-414. doi: 10.1016/j.immuni.2012.01.009

Shio, M. T., Eisenbarth, S. C., Savaria, M., Vinet, A. F., Bellemare, M. J., Harder, K. W., et al. (2009). Malarial hemozoin activates the NLRP3 inflammasome through Lyn and Syk kinases. PLoS Pathog. 5:e1000559. doi: 10.1371/journal.ppat.1000559

Silva, G., Jeney, V., Chora, A., Larsen, R., Balla, J., and Soares, M. P. (2009). Oxidized hemoglobin is an endogenous proinflammatory agonist that targets vascular endothelial cells. J. Biol. Chem. 284, 29582-29595. doi: 10.1074/jbc.M109.045344

Silva-Gomes, S., Appelberg, R., Larsen, R., Soares, M. P., and Gomes, M. S. (2013). Heme catabolism by heme oxygenase- 1 confers host resistance to Mycobacterium infection. Infect. Immun. 81, 2536-2545. doi: 10.1128/IAI.00251-13

Simionatto, C. S., Cabal, R., Jones, R. L., and Galbraith, R. A. (1988). Thrombophlebitis and disturbed hemostasis following administration of intravenous hematin in normal volunteers. Am. J. Med. 85, 538-540. doi: 10.1016/S0002 9343(88)80092-5

Sindrilaru, A., Peters, T., Wieschalka, S., Baican, C., Baican, A., Peter, H., et al. (2011). An unrestrained proinflammatory M1 macrophage population induced by iron impairs wound healing in humans and mice. J. Clin. Invest. 121, 985-997. doi: $10.1172 /$ JCI44490

Slater, A. F. (1992). Malaria pigment. Exp. Parasitol. 74, 362-365. doi: 10.1016/00144894(92)90162-4

Slater, A. F., Swiggard, W. J., Orton, B. R., Flitter, W. D., Goldberg, D. E., Cerami, A., et al. (1991). An iron-carboxylate bond links the heme units of malaria pigment. Proc. Natl. Acad. Sci. U.S.A. 88, 325-329. doi: 10.1073/pnas.88.2.325

Sluimer, J. C., Gasc, J. M., van Wanroij, J. L., Kisters, N., Groeneweg, M., Sollewijn Gelpke, M. D., et al. (2008). Hypoxia, hypoxia-inducible transcription factor, and macrophages in human atherosclerotic plaques are correlated with intraplaque angiogenesis. J. Am. Coll. Cardiol. 51, 1258-1265. doi: 10.1016/j.jacc.2007. 12.025

Sluimer, J. C., Kolodgie, F. D., Bijnens, A. P., Maxfield, K., Pacheco, E., Kutys, B., et al. (2009). Thin-walled microvessels in human coronary atherosclerotic plaques show incomplete endothelial junctions relevance of compromised structural integrity for intraplaque microvascular leakage. J. Am. Coll. Cardiol. 53, 1517-1527. doi: 10.1016/j.jacc.2008.12.056

Spirito, P., and Maron, B. J. (1990). Relation between extent of left ventricular hypertrophy and occurrence of sudden cardiac death in hypertrophic cardiomyopathy. J. Am. Coll. Cardiol. 15, 1521-1526. doi: 10.1016/0735-1097(90)92820-R

Stewart, C. R., Stuart, L. M., Wilkinson, K., van Gils, J. M., Deng, J., Halle, A., et al. (2010). CD36 ligands promote sterile inflammation through assembly of a Toll-like receptor 4 and 6 heterodimer. Nat. Immunol. 11, 155-161. doi: 10.1038/ni.1836

Sukumari-Ramesh, S., Laird, M. D., Singh, N., Vender, J. R., Alleyne, C. H. Jr., et al. (2010). Astrocyte-derived glutathione attenuates hemin-induced apoptosis in cerebral microvascular cells. Glia 58, 1858-1870. doi: 10.1002/glia.21055

Takeuchi, O., and Akira, S. (2010). Pattern recognition receptors and inflammation. Cell 140, 805-820. doi: 10.1016/j.cell.2010.01.022
Tang, X. D., Xu, R., Reynolds, M. F., Garcia, M. L., Heinemann, S. H., and Hoshi, T. (2003). Haem can bind to and inhibit mammalian calcium-dependent Slol BK channels. Nature 425, 531-535. doi: 10.1038/nature02003

Tappel, A. L. (1953). The mechanism of the oxidation of unsaturated fatty acids catalyzed by hematin compounds. Arch. Biochem. Biophys. 44, 378-395. doi: 10.1016/0003-9861(53)90056-3

Tappel, A. L. (1955). Unsaturated lipid oxidation catalyzed by hematin compounds. J. Biol. Chem. 217, 721-733.

Taylor, K. R., Yamasaki, K., Radek, K. A., Di Nardo, A., Goodarzi, H., Golenbock, D., et al. (2007). Recognition of hyaluronan released in sterile injury involves a unique receptor complex dependent on Toll-like receptor 4, CD44, and MD-2. J. Biol. Chem. 282, 18265-18275. doi: 10.1074/jbc.M606352200

Teng, W., Wang, L., Xue, W., and Guan, C. (2009). Activation of TLR4-mediated NFkappaB signaling in hemorrhagic brain in rats. Mediators Inflamm. 2009, 473276. doi: 10.1155/2009/473276

Tenhunen, R., Marver, H. S., and Schmid, R. (1968). The enzymatic conversion of heme to bilirubin by microsomal heme oxygenase. Proc. Natl. Acad. Sci. U.S.A. 61, 748-755. doi: 10.1073/pnas.61.2.748

Thornberry, N. A., Bull, H. G., Calaycay, J. R., Chapman, K. T., Howard, A. D., Kostura, M. J., et al. (1992). A novel heterodimeric cysteine protease is required for interleukin-1 beta processing in monocytes. Nature 356, 768-774. doi: $10.1038 / 356768 \mathrm{a} 0$

Tolosano, E., Fagoonee, S., Morello, N., Vinchi, F., and Fiorito, V. (2010). Heme scavenging and the other facets of hemopexin. Antioxid. Redox Signal. 12, 305320. doi: 10.1089/ars.2009.2787

Tolosano, E., Hirsch, E., Patrucco, E., Camaschella, C., Navone, R., Silengo, L., et al. (1999). Defective recovery and severe renal damage after acute hemolysis in hemopexin-deficient mice. Blood 94, 3906-3914.

Tsukihara, T., Aoyama, H., Yamashita, E., Tomizaki, T., Yamaguchi, H., ShinzawaItoh, K., etal. (1995). Structures of metal sites of oxidized bovine heart cytochrome $c$ oxidase at 2.8 A. Science 269, 1069-1074. doi: 10.1126/science.7652554

Turnbull, I. R., McDunn, J. E., Takai, T., Townsend, R. R., Cobb, J. P., and Colonna, M. (2005). DAP12 (KARAP) amplifies inflammation and increases mortality from endotoxemia and septic peritonitis. J. Exp. Med. 202, 363-369. doi: 10.1084/jem.20050986

Underhill, D. M., and Goodridge, H. S. (2007). The many faces of ITAMs. Trends Immunol. 28, 66-73. doi: 10.1016/j.it.2006.12.004

Van der Zee, J., Barr, D. P., and Mason, R. P. (1996). ESR spin trapping investigation of radical formation from the reaction between hematin and tert-butyl hydroperoxide. Free Radic. Biol. Med. 20, 199-206. doi: 10.1016/0891-5849(95)02031-4

Vile, G. F., Basu-Modak, S., Waltner, C., and Tyrrell, R. M. (1994). Heme oxygenase 1 mediates an adaptive response to oxidative stress in human skin fibroblasts. Proc. Natl. Acad. Sci. U.S.A. 91, 2607-2610. doi: 10.1073/pnas.91.7.2607

Vincent, S. H. (1989). Oxidative effects of heme and porphyrins on proteins and lipids. Semin. Hematol. 26, 105-113.

Vincent, S. H., Grady, R. W., Shaklai, N., Snider, J. M., and Muller-Eberhard, U. (1988). The influence of heme-binding proteins in heme-catalyzed oxidations. Arch. Biochem. Biophys. 265, 539-550. doi: 10.1016/0003-9861(88)90159-2

Vinchi, F., De Franceschi, L., Ghigo, A., Townes, T., Cimino, J., Silengo, L., etal. (2013). Hemopexin therapy improves cardiovascular function by preventing heme-induced endothelial toxicity in mouse models of hemolytic diseases. Circulation 127, 1317-1329. doi: 10.1161/CIRCULATIONAHA.112. 130179

Vinchi, F., Gastaldi, S., Silengo, L., Altruda, F., and Tolosano, E. (2008). Hemopexin prevents endothelial damage and liver congestion in a mouse model of heme overload. Am. J. Pathol. 173, 289-299. doi: 10.2353/ajpath.2008.071130

Virmani, R., Kolodgie, F. D., Burke, A. P., Finn, A. V., Gold, H. K., Tulenko, T. N., et al. (2005). Atherosclerotic plaque progression and vulnerability to rupture: angiogenesis as a source of intraplaque hemorrhage. Arterioscler. Thromb. Vasc. Biol. 25, 2054-2061. doi: 10.1161/01.ATV.0000178991.71605.18

Vojtechovsky, J., Chu, K., Berendzen, J., Sweet, R. M., and Schlichting, I. (1999). Crystal structures of myoglobin-ligand complexes at near-atomic resolution. Biophys. J. 77, 2153-2174. doi: 10.1016/S0006-3495(99)77056-6

von Bruhl, M. L., Stark, K., Steinhart, A., Chandraratne, S., Konrad, I., Lorenz, M., et al. (2012). Monocytes, neutrophils, and platelets cooperate to initiate and propagate venous thrombosis in mice in vivo. J. Exp. Med. 209, 819-835. doi: $10.1084 /$ jem.20112322 
Wagener, F. A., Abraham, N. G., van Kooyk, Y., de Witte, T., and Figdor, C. G. (2001a). Heme-induced cell adhesion in the pathogenesis of sickle-cell disease and inflammation. Trends Pharmacol. Sci. 22, 52-54. doi: 10.1016/S0165-6147(00)01609-6

Wagener, F. A., Eggert, A., Boerman, O. C., Oyen, W. J., Verhofstad, A., Abraham, N. G., et al. (2001b). Heme is a potent inducer of inflammation in mice and is counteracted by heme oxygenase. Blood 98, 1802-1811. doi: 10.1182/blood.V98.6.1802

Wagener, F. A., Feldman, E., de Witte, T., and Abraham, N. G. (1997). Heme induces the expression of adhesion molecules ICAM-1, VCAM-1, and E selectin in vascular endothelial cells. Proc. Soc. Exp. Biol. Med. 216, 456-463. doi: 10.3181/00379727-216-44197

Wagener, F. A., van Beurden, H. E., von den Hoff, J. W., Adema, G. J., and Figdor, C. G. (2003a). The heme-heme oxygenase system: a molecular switch in wound healing. Blood 102, 521-528. doi: 10.1182/blood-2002-07-2248

Wagener, F. A., Volk, H. D., Willis, D., Abraham, N. G., Soares, M. P., Adema, G. J., et al. (2003b). Different faces of the heme-heme oxygenase system in inflammation. Pharmacol. Rev. 55, 551-571. doi: 10.1124/pr.55.3.5

Wang, J., and Doré, S. (2007). Heme oxygenase-1 exacerbates early brain injury after intracerebral haemorrhage. Brain 130, 1643-1652. doi: 10.1093/brain/awm095

Wang, Y. C., Wang, P. F., Fang, H., Chen, J., Xiong, X. Y., and Yang, Q. W. (2013). Tolllike receptor 4 antagonist attenuates intracerebral hemorrhage-induced brain injury. Stroke 44, 2545-2552. doi: 10.1161/STROKEAHA.113.001038

Wen, H., Miao, E. A., and Ting, J. P. (2013). Mechanisms of NOD-like receptor-associated inflammasome activation. Immunity 39, 432-441. doi: 10.1016/j.immuni.2013.08.037

Wesche, H., Henzel, W. J., Shillinglaw, W., Li, S., and Cao, Z. (1997). MyD88: an adapter that recruits IRAK to the IL-1 receptor complex. Immunity 7, 837-847. doi: 10.1016/S1074-7613(00)80402-1

Wu, M. L., Ho, Y. C., Lin, C. Y., and Yet, S. F. (2011). Heme oxygenase-1 in inflammation and cardiovascular disease. Am. J. Cardiovasc. Dis. 1, 150-158.

Xi, G., Keep, R. F., and Hoff, J. T. (2006). Mechanisms of brain injury after intracerebral haemorrhage. Lancet Neurol. 5, 53-63. doi: 10.1016/S1474-4422(05)70283-0

Xia, D., Yu, C. A., Kim, H., Xia, J. Z., Kachurin, A. M., Zhang, L., et al. (1997). Crystal structure of the cytochrome bcl complex from bovine heart mitochondria. Science 277, 60-66. doi: 10.1126/science.277.5322.60

Xue, H., Guo, H., Li, Y. C., and Hao, Z. M. (2007). Heme oxygenase-1 induction by hemin protects liver cells from ischemia/reperfusion injury in cirrhotic rats. World J. Gastroenterol. 13, 5384-5390.

Yachie, A., Niida, Y., Wada, T., Igarashi, N., Kaneda, H., Toma, T., et al. (1999). Oxidative stress causes enhanced endothelial cell injury in human heme oxygenase-1 deficiency. J. Clin. Invest. 103, 129-135. doi: 10.1172/JCI4165

Yamamoto, M., Sato, S., Hemmi, H., Hoshino, K., Kaisho, T., Sanjo, H., etal. (2003). Role of adaptor TRIF in the MyD88-independent Toll-like receptor signaling pathway. Science 301, 640-643. doi: 10.1126/science. 1087262

Yanai, H., Savitsky, D., Tamura, T., and Taniguchi, T. (2009). Regulation of the cytosolic DNA-sensing system in innate immunity: a current view. Curr. Opin. Immunol. 21, 17-22. doi: 10.1016/j.coi.2009.01.005

Yang, H., Wang, H., Bernik, T. R., Ivanova, S., Ulloa, L., Roth, J., et al. (2002). Globin attenuates the innate immune response to endotoxin. Shock 17, 485-490. doi: 10.1097/00024382-200206000-00008

Yoriki, H., Naito, Y., Takagi, T., Mizusima, K., Hirai, Y., Harusato, A., et al. (2013). Hemin ameliorates indomethacin-induced small intestinal injury in mice through the induction of heme oxygenase-1. J. Gastroenterol. Hepatol. 28, 632-638. doi: 10.1111/jgh.12074

Yu, L., Wang, L., and Chen, S. (2010). Endogenous Toll-like receptor ligands and their biological significance. J. Cell. Mol. Med. 14, 2592-2603. doi: 10.1111/j.15824934.2010.01127.x

Zawrotniak, M., and Rapala-Kozik, M. (2013). Neutrophil extracellular traps (NETs) - formation and implications. Acta Biochim. Pol. 60, 277-284.

Zhang, D. W., Shao, J., Lin, J., Zhang, N., Lu, B. J., Lin, S. C., et al. (2009). RIP3, an energy metabolism regulator that switches TNF-induced cell death from apoptosis to necrosis. Science 325, 332-336. doi: 10.1126/science.1172308

Zhang, Z., Huang, L., Shulmeister, V. M., Chi, Y. I., Kim, K. K., Hung, L. W., et al. (1998). Electron transfer by domain movement in cytochrome bcl. Nature 392, 677-684. doi: 10.1038/33612

Zhou, R., Yazdi, A. S., Menu, P., and Tschopp, J. (2011). A role for mitochondria in NLRP3 inflammasome activation. Nature 469, 221-225. doi: 10.1038 /nature09663

Conflict of Interest Statement: The authors declare that the research was conducted in the absence of any commercial or financial relationships that could be construed as a potential conflict of interest.

Received: 09 March 2014; paper pending published: 03 April 2014; accepted: 29 April 2014; published online: 27 May 2014.

Citation: Dutra FF and Bozza MT (2014) Heme on innate immunity and inflammation. Front. Pharmacol. 5:115. doi: 10.3389/fphar.2014.00115

This article was submitted to Drug Metabolism and Transport, a section of the journal Frontiers in Pharmacology.

Copyright (c) 2014 Dutra and Bozza. This is an open-access article distributed under the terms of the Creative Commons Attribution License (CC BY). The use, distribution or reproduction in other forums is permitted, provided the original author(s) or licensor are credited and that the original publication in this journal is cited, in accordance with accepted academic practice. No use, distribution or reproduction is permitted which does not comply with these terms. 